Article

\title{
Patterns of Variation and Chemosystematic Significance of Phenolic Compounds in the Genus Cyclopia (Fabaceae, Podalyrieae)
}

\author{
Maria. A. Stander ${ }^{1,2, *(\mathbb{D})}$, Herman Redelinghuys ${ }^{3} \mathbb{D}$, Keabetswe Masike ${ }^{1}$, Helen Long $^{4}$ and \\ Ben-Erik Van Wyk ${ }^{4}$ \\ 1 Department of Biochemistry, University of Stellenbosch, Private Bag X1, Matieland 7600, South Africa; \\ kmasike@sun.ac.za \\ 2 Mass Spectrometry Unit, Central Analytical Facility, University of Stellenbosch, Private Bag X1, \\ Matieland 7600, South Africa \\ 3 CREST (Centre for Research on Evaluation, Science and Technology), University of Stellenbosch, \\ Private Bag X1, Matieland 7600, South Africa; hredelinghuys@sun.ac.za \\ 4 Department of Botany and Plant Biotechnology, University of Johannesburg, P.O. Box 524, Auckland Park, \\ Johannesburg 2006, South Africa; phytomed@uj.ac.za (H.L.); bevanwyk@uj.ac.za (B.-E.V.W.) \\ * Correspondence: Lcms@sun.ac.za; Tel.: +27-21-808-5825
}

Received: 2 May 2019; Accepted: 6 June 2019; Published: 26 June 2019

\begin{abstract}
As a contribution towards a better understanding of phenolic variation in the genus Cyclopia (honeybush tea), a collection of 82 samples from 15 of the 23 known species was analysed using liquid-chromatography-high resolution mass spectrometry (UPLC-HRMS) in electrospray ionization (ESI) negative mode. Mangiferin and isomangiferin were found to be the main compounds detected in most samples, with the exception of C. bowiena and C. buxifolia where none of these compounds were detected. These xanthones were found to be absent from the seeds and also illustrated consistent differences between species and provenances. Results for contemporary samples agreed closely with those based on analysis of a collection of ca. 30-year-old samples. The use of multivariate tools allowed for graphical visualizations of the patterns of variation as well as the levels of the main phenolic compounds. Exclusion of mangiferin and citric acid from the data was found to give better visual separation between species. The use of UPLC-HRMS generated a large dataset that allowed for comparisons between species, provenances and plant parts (leaves, pods, flowers and seeds). Phenetic analyses resulted in groupings of samples that were partly congruent with species but not with morphological groupings within the genus. Although different provenances of the same species were sometimes found to be very variable, Principle Component Analysis (PCA) indicated that a combination of compounds have some (albeit limited) potential as diagnostic characters at species level. 74 Phenolic compounds are presented, many of which were identified for the first time in Cyclopia species, with nine of these being responsible for the separation between samples in the PCAs.
\end{abstract}

Keywords: Cyclopia; honeybush tea; phenolic compounds; orobol; butein; mangiferin; LCMS; isosakuranetin; multivariate data analysis

\section{Introduction}

Cyclopia Vent. is a fynbos-endemic genus of legumes (family Fabaceae, tribe Podalyrieae) comprising 23 known species. Several species have a long history of traditional use as herbal teas [1] but it is only recently that commercial crop and product development has been initiated [2,3], focused mainly on C. genistoides (L.) R.Br., C. intermedia E.Mey. and C. subternata Vogel. These three species are 
generally referred to as heuningbostee, bergtee and vleitee, respectively. Other species such as C. sessilifolia Eckl. \& Zeyh. (Heidelbergtee) and C. maculata (Andrews) Kies (Genadendaltee) have also been used to a limited extent [4-8]. The species are superficially rather similar, resulting in a confused taxonomy and nomenclature [4-7]. Infrageneric relationships are complicated by the fire-survival strategies of the species because the distinction between seeding and sprouting is not always clear, and some overlap seems to occur [6]. Based on extensive field studies in the early 1990's, a detailed revision of the genus was published, in which the delimitation and geographical distribution of the species were clarified [7]. As part of a broader chemosystematic study of Cape genistoid legumes, reviewed in 2003 [9], an attempt was made to compare Cyclopia with other genera of the tribe Podalyrieae. It was found that Cyclopia species do not accumulate quinolizidine alkaloids as is typical for other genera, but that the leaves were rich in phenolic compounds. Cyclopia proved to be chemically distinct from other genera of the tribe, indicating an isolated phylogenetic position [10-13]. De Nysschen and co-workers [14] were the first to isolate and describe mangiferin as the main phenolic compound, which co-occurred with hesperitin and isosakuretin in leaves. Another study [15] showed that butein, 3'hydroxydaidzein and other flavonoids are the main seed metabolites, not only in Cyclopia but also in other genera of the tribe. The HPLC system used at that time [14], [15] did not provide sufficiently accurate quantitative data to distinguish between the species.

Liquid-chromatography-high resolution mass spectrometry (UPLC-HRMS) has previously been used for the analysis of C. subternata [16-18] and C. genistoides [19], but as yet, no studies have been conducted into the full extent of chemical variation in the rest of the genus (including the non-commercial species). It was decided to reinvestigate Cyclopia species with the aim of not only describing the phenolic variation in the genus (which is relevant to developing better quality control analyses) but also to have another attempt at evaluating the chemosystematic significance of the main phenolic compounds. Several authentic samples used by Schutte [7] in her revision of the genus were available for study. The aim was to determine if different species and populations of Cyclopia could be distinguished by quantitative and perhaps also qualitative differences in their overall phenolic profiles.

\section{Results and Discussion}

Table 1 lists the main compounds detected, while Table 2 contains a list of the samples, their species, voucher numbers and collection localities. Figure 1 shows the total ion chromatograms of four different Cyclopia species and highlights the differences in phenolic profiles that were detected. The tentative identification of compounds was based on previous papers [16-26], as well as a combination of fragmentation data, elemental composition based on accurate mass, relative retention times and UV data.

\subsection{Tentative Identification of New Compounds in Cyclopia in Table 1}

Two isomeric peaks with $m / z 429[\mathrm{M}-\mathrm{H}]^{-},\left(\mathrm{C}_{19} \mathrm{H}_{25} \mathrm{O}_{11}\right)$, from compounds 12 and 13, eluted at retention times (Rts) of 11.21 and 11.39 min respectively. The $\mathrm{MS}^{\mathrm{E}}$ spectra at higher collision energy (function 2) showed an intense fragment ion (base peak or bp) at $m / z 135\left(\mathrm{C}_{8} \mathrm{H}_{7} \mathrm{O}_{2}\right)$ for both peaks. The molecular formula for this fragment ion corresponds to that of piceol (4-hydroxyacetophenone), previously identified in the methanolic extracts of Cyclopia genistoides [20]. Metabolites 12 and 13 were thus tentatively annotated as piceol-O-hexose-O-pentoside isomers, with the piceol fragment ion being produced by neutral loss of a disaccharide moiety (-294 Da) consisting of hexose (-162 Da) and pentose (-132 Da) subunits.

At Rt $11.68 \mathrm{~min}$, a peak with a $m / z$ of $443[\mathrm{M}-\mathrm{H}]^{-},\left(\mathrm{C}_{20} \mathrm{H}_{27} \mathrm{O}_{11}\right)$, compound 16, was observed, with corresponding fragment ions at $m / z 135$ and 96 . It is not clear what the ion at $m / z 96$ represents, but the calculated molecular formula of the $m / z 135$ fragment corresponds to that of piceol (as discussed above), arising from the neutral loss of a disaccharide moiety ( $-308 \mathrm{Da}$ ) with hexose and rhamnoside (-146 Da) subunits. Thus, this peak was tentatively annotated as piceol-O-hexose-O-rhamnoside. 
Compound 51, eluting at Rt 20.17 min presented a precursor ion at $m / z 445[\mathrm{M}-\mathrm{H}]^{-},\left(\mathrm{C}_{22} \mathrm{H}_{21} \mathrm{O}_{10}\right)$, which under $\mathrm{MS}^{\mathrm{E}}$ fragmentation showed fragment ions at $\mathrm{m} / \mathrm{z} 283[\mathrm{M}-\mathrm{H}]^{-},\left(\mathrm{C}_{16} \mathrm{H}_{11} \mathrm{O}_{5}\right), 286$ and 239. The molecular formula of the aglycone fragment at $\mathrm{m} / \mathrm{z} 283$ corresponds to the isoflavone olmelin (biochanin A) [22], produced by neutral loss of a hexose moiety, whilst the ion at $m / z 268$ results from the further neutral loss of the methyl $(-15 \mathrm{Da})$ group. Thus, this peak was tentatively annotated as olmelin (biochanin A)-O-hexoside.

At Rt 21.16 min, a peak with $\mathrm{m} / \mathrm{z} 271[\mathrm{M}-\mathrm{H}]^{-},\left(\mathrm{C}_{15} \mathrm{H}_{11} \mathrm{O}_{5}\right)$, compound 56, was observed, with fragment ions of $\mathrm{m} / \mathrm{z} 135$ and 91 which are characteristic of both the flavanone butin and the chalcone butein [23]. Compound 56 was thus tentatively annotated as butin/butein. Two isomeric peaks eluting at Rt 22.39 and 23.49 min with a $\mathrm{m} / \mathrm{z} 433\left[\mathrm{M}-\mathrm{H}^{-},\left(\mathrm{C}_{21} \mathrm{H}_{21} \mathrm{O}_{10}\right)\right.$ were observed. The $\mathrm{MS}^{\mathrm{E}}$ spectra showed fragment ions similar to those observed for butin/butein, namely 271,135 and 91 . Since the fragment ion at $\mathrm{m} / \mathrm{z} 271$ results from the neutral loss of a hexose moiety, these peaks were tentatively annotated as butin/butein-O-hexoside isomers.

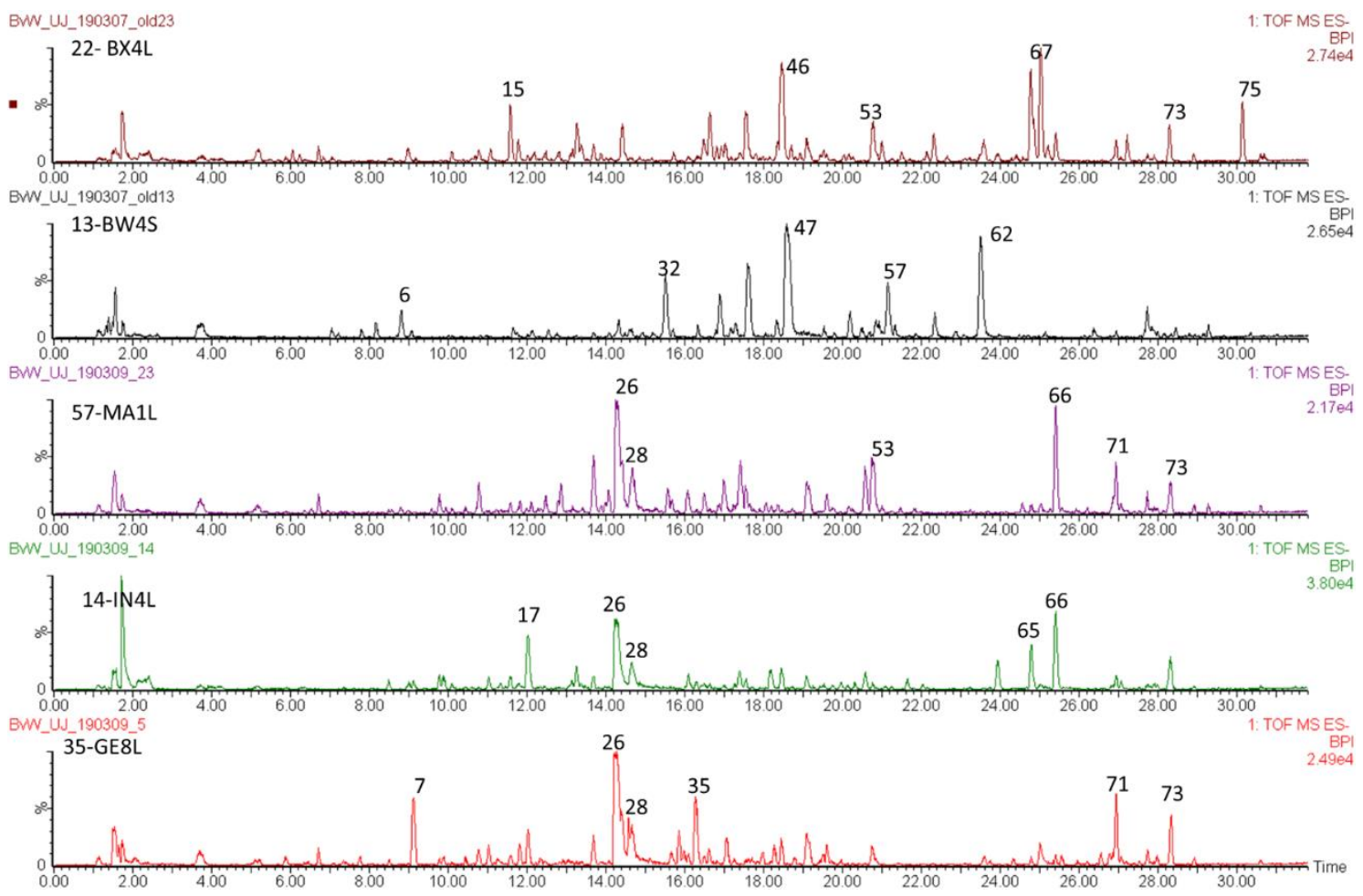

Figure 1. Total ion chromatograms of extracts of (from top down): Cyclopia buxifolia (Burm.f.) Kies leaves from Jonkershoek (BX4L); Cyclopia bowieana Harv. stems from Ruitersberg (BW4S); Cyclopia maculata (Andrews) Kies leaves from Garcia State Forest (MA1L); Cyclopia intermedia E.Mey. leaves from Oudtshoorn (IN4L); Cyclopia genistoides (L.) R.Br. leaves from Bettys Bay (GE8L) showing large differences in their phenolic profiles with mangiferin (compound 26) absent in the top two plant extracts.

\subsection{Levels of Main Compounds}

Figure 2 consists of a heatmap of the main compounds detected in the samples, showing the higher concentration compounds in lighter shades and low concentrations in dark, note the many light blocks for citric acid and mangiferin. Since calibration standards are not available for the majority of compounds detected, the peak areas for these compounds were converted to concentration values in $\mathrm{mg} / \mathrm{kg}$ by interpolation off the mangiferin calibration curve and are provided in the Supplementary data, Table S1. Mangiferin levels in the plant extracts were found to be above the linear range of the mass spectrometer and their concentrations in this table should therefore be seen as relative. The mangiferin levels of 30 of the samples were more accurately determined using UV detection at 
$280 \mathrm{~nm}$. Concentrations of between 0.41 and $3.8 \mathrm{~g} / 100 \mathrm{~g}$ were recorded in the samples where the compound was present (Results not shown).

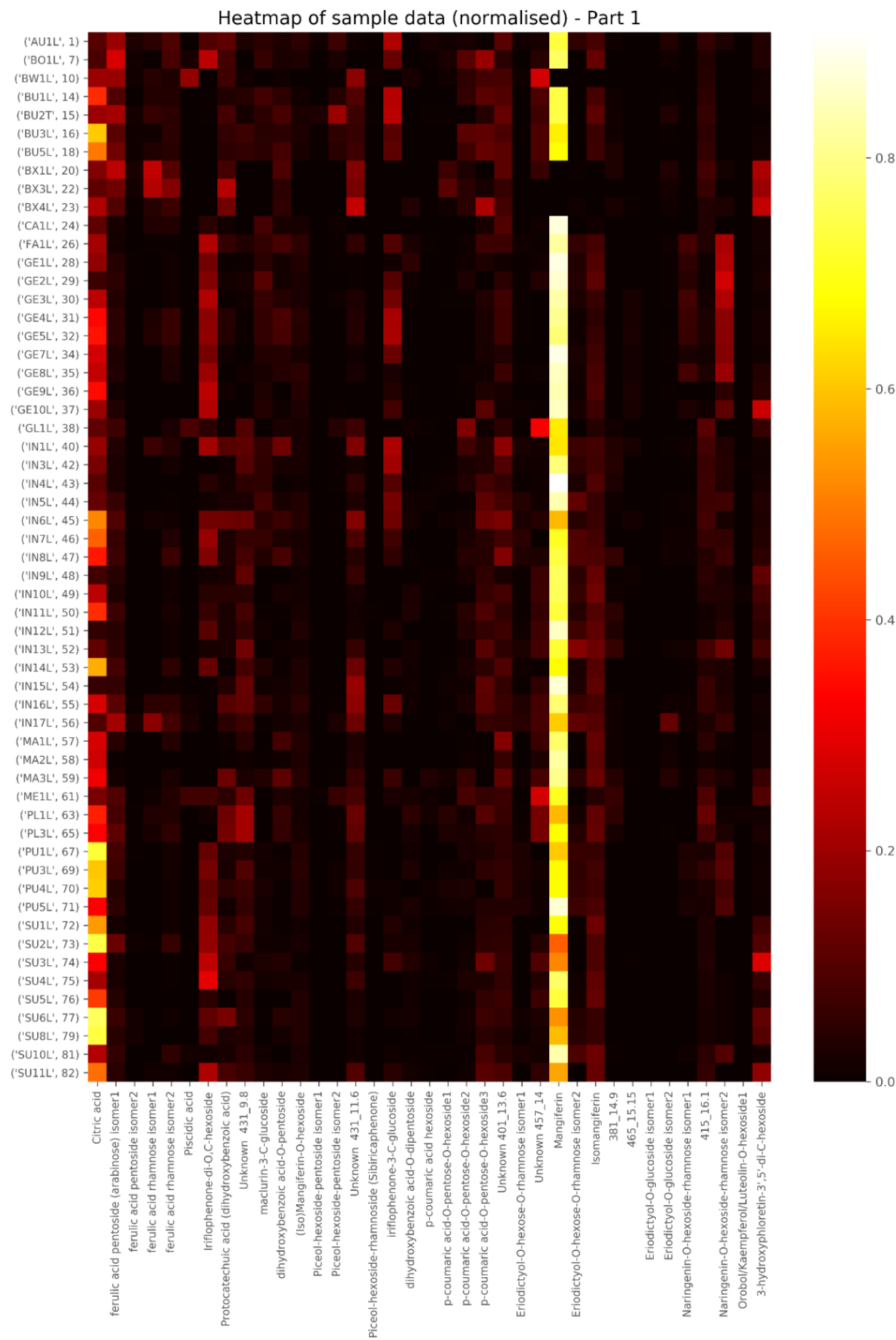

Figure 2. Cont. 


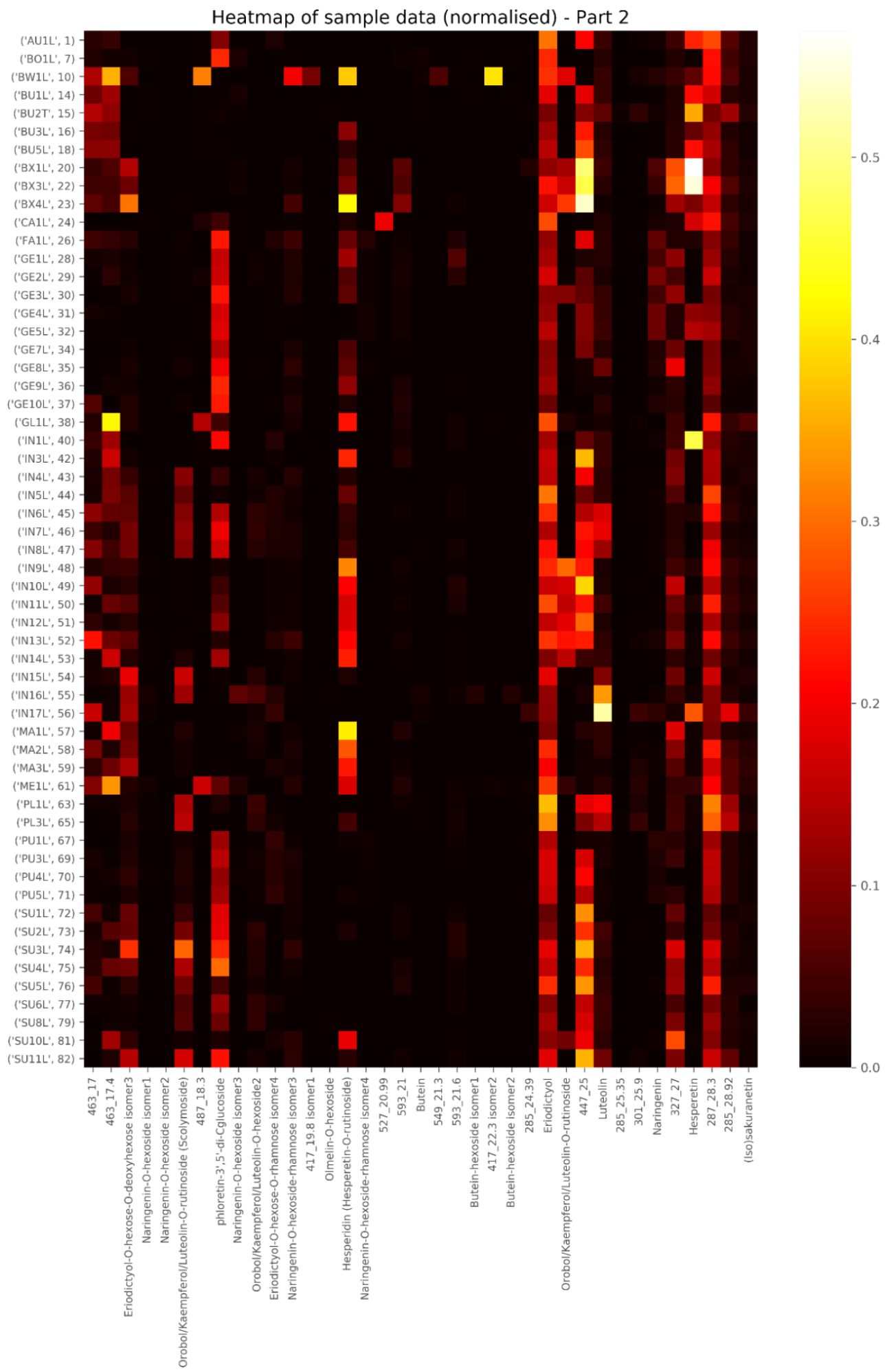

Figure 2. Heatmap of the main peaks detected in the Cyclopia extracts, showing mangiferin as the most abundant phenolic compound in most samples (light vertical line). The lighter the spot, the higher the concentration. C. aurescens (AU), C. bolusii (BO), C. bowiena (BW), C. burtonii (BU), C. buxifolia (BX), C. capensis (CA), C. falcata (FA), C. genistoides (GE), C. glabra (GL), C. intermedia (IN), C. maculata (MA), C. meyeriana (ME), C. plicata (PL), C. pubescens (PU) and C. subternata (SU); ( $=$ leaves, $\mathrm{T}=$ twigs, $\mathrm{P}=$ pods, $\mathrm{S}=$ seeds); Sample numbering is according to sample locality from West to East per species. 
The phenolic metabolites of Cyclopia species that have been commercialized (C. subternata, C. genistoides, C. intermedia) have been well studied and the results thereof published extensively [16-20,24]. In addition, some mention is also made of C. sessiliflora and C. maculata which are also commercially processed, albeit on a smaller scale [18,25]. Walters et al. [21] investigated the phenolic composition of the non-utilised species C. pubescens and detected the xanthones mangiferin and isomangiferin as some of the main compounds. The same authors also detected flavanones, a flavone and benzophenones. Methylated flavonoids including the isoflavone, formononetin and afrormozin as reported by [20] in C. subternata were not reported by other investigators. The reported presence [14] of (iso)sakuranetin and hesperitin, which elute rather late in the chromatogram was confirmed in this study (Table 1). It is possible that these compounds may not elute off the $\mathrm{C}_{18}$ column of a modern reverse-phase chromatographic system, since the work of earlier investigators was performed on normal phase systems. This scenario was investigated by extracting one sample with solvents of different polarity (methanol, dichloromethane, dimethylsulfoxide, ethanol, water and combinations of these). The analysis was then repeated using the current method as well as on a much shorter column using a stronger gradient. The results showed a lower extraction efficiency of early eluting polar molecules and a higher extraction efficiency for non-polar late eluting molecules when using stronger solvents. For example, 20\% more luteolin and 33\% less mangiferin was extracted using methanol/dichloromethane compared to 50\% methanol. No other methoxylated flavonoids were detected using this solvent system, only some hydroxylated long chain fatty acids were detected (Figure 3).

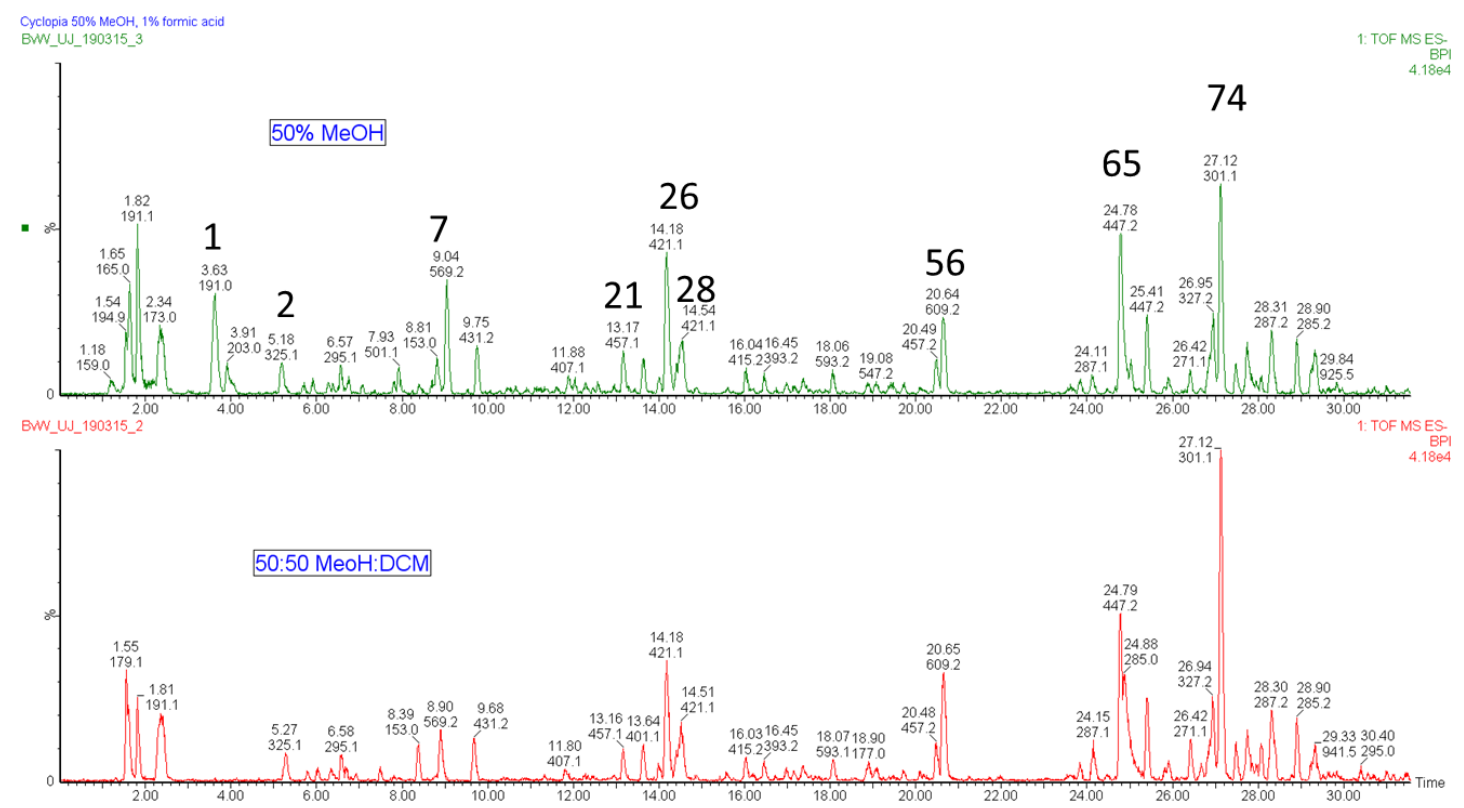

Figure 3. Total ion chromatogram of Cyclopia subternata extract of methanol/dichloromethane (1:1, bottom) and $50 \%$ methanol, $1 \%$ formic acid (top) showing different extraction efficiencies according to the polarity of the analytes. 
Table 1. List of compounds tentatively identified in Cyclopia extracts in this study showing compound number, retention time, detected [M-H] ion, elemental composition and $\mathrm{MS}^{\mathrm{E}}$ fragments as well as literature references to where the compounds were previously detected.

\begin{tabular}{|c|c|c|c|c|c|c|}
\hline & Retention Time & Exprimental $\mathrm{m} / \mathrm{z}$ & Formula & MS $^{\mathrm{E}}$ Fragments & & Reference \\
\hline 1 & 3.64 & 191.0197 & $\mathrm{C}_{6} \mathrm{H}_{7} \mathrm{O}_{7}$ & 191.0197,111.0087,87.0082,85.0303 & ${ }^{*}$ Citric acid & New \\
\hline 2 & 5.18 & 325.1131 & $\mathrm{C}_{12} \mathrm{H}_{21} \mathrm{O}_{10}$ & 325.1143,193.0726,161.0428,101.0237 & Ferulic acid pentoside (arabinose) isomer1 & New \\
\hline 3 & 5.73 & 325.1127 & $\mathrm{C}_{12} \mathrm{H}_{21} \mathrm{O}_{10}$ & 325.1143,193.0712,161.0491,101.0237 & Ferulic acid pentoside isomer2 & New \\
\hline 4 & 6.06 & 339.1286 & $\mathrm{C}_{13} \mathrm{H}_{23} \mathrm{O}_{10}$ & 339.1292,193.0725,161.0461,101.0260 & Ferulic acid rhamnose isomer1 & New \\
\hline 5 & 6.72 & 339.1286 & $\mathrm{C}_{13} \mathrm{H}_{23} \mathrm{O}_{10}$ & $339.1268,207.0880,178.8859,161.0460,113.0221,101.0234$ & Ferulic acid rhamnose isomer2 & New \\
\hline 7 & 9.13 & 569.1503 & $\mathrm{C}_{25} \mathrm{H}_{29} \mathrm{O}_{15}$ & $569.1558,449.1093,287.0552,167.0341,125.0242$ & $\begin{array}{l}\text { Iriflophenone-di-O,C-hexoside } \\
\text { (3- } \beta \text {-D-glucopyranosyl-4- } \beta \text {-D-glucopyranosyloxyiriflophenone) }\end{array}$ & [18-21] \\
\hline 8 & 8.98 & 153.0189 & $\mathrm{C}_{7} \mathrm{H}_{5} \mathrm{O}_{4}$ & 153.0192,109.0305 & *Protocatechuic acid (dihydroxybenzoic acid) & New \\
\hline 9 & 9.79 & 431.1552 & $\mathrm{C}_{19} \mathrm{H}_{27} \mathrm{O}_{11}$ & $431.1524,293.0834,233.0672,89.0247$ & Unknown 431_9.8 & New \\
\hline 10 & 9.87 & 423.0922 & $\mathrm{C}_{19} \mathrm{H}_{19} \mathrm{O}_{11}$ & 423.0932,303.0525,193.0142,109.0294 & Maclurin-3-C-glucoside (3- $\beta$-D-glucopyranosylmaclurin) & [18-21] \\
\hline 11 & 10.77 & 285.0621 & $\mathrm{C}_{12} \mathrm{H}_{13} \mathrm{O}_{8}$ & $285.0622,153.0184,152.0117,109.0285,108.0222$ & Dihydroxybenzoic acid-O-pentoside & [19] \\
\hline 13 & 11.21 & 429.1401 & $\mathrm{C}_{19} \mathrm{H}_{25} \mathrm{O}_{11}$ & $429.1383, \mathbf{1 3 5 . 0 4 5 2}$ & Piceol-hexoside-pentoside isomer1 & New \\
\hline 14 & 11.39 & 429.1400 & $\mathrm{C}_{19} \mathrm{H}_{25} \mathrm{O}_{11}$ & $429.1404,293.0877,233.0666,135.0456$ & Piceol-hexoside-pentoside isomer2 & New \\
\hline 15 & 11.58 & 431.1555 & $\mathrm{C}_{19} \mathrm{H}_{27} \mathrm{O}_{11}$ & 431.1552,275.0564,163.0406,119.0432 & Unknown 431_11.6 & New \\
\hline 16 & 11.68 & 443.1558 & $\mathrm{C}_{20} \mathrm{H}_{27} \mathrm{O}_{11}$ & $135.0453,96.9698$ & Piceol-hexoside-rhamnoside (Sibiricaphenone) & New \\
\hline 17 & 12.04 & 407.0981 & $\mathrm{C}_{19} \mathrm{H}_{19} \mathrm{O}_{10}$ & $407.0979,317.0664,287.0555,245.0453,193.0129,125.0247$ & Iriflophenone-3-C-glucoside (3- $\beta$-D-glucopyranosyliriflophenone) & [18-21] \\
\hline 18 & 12.15 & 417.1046 & $\mathrm{C}_{17} \mathrm{H}_{21} \mathrm{O}_{12}$ & 417.1038,153.0178,152.0110,109.0285,108.0222 & Dihydroxybenzoic acid-O-dipentoside & [19] \\
\hline 19 & 12.47 & 325.0918 & $\mathrm{C}_{15} \mathrm{H}_{17} \mathrm{O}_{8}$ & 325.0942,163.0406,119.0503 & $p$-Coumaric acid hexoside & New \\
\hline 20 & 12.8 & 457.1352 & $\mathrm{C}_{20} \mathrm{H}_{25} \mathrm{O}_{12}$ & 457.1357,163.0401,119.0498 & $p$-coumaric acid-O-pentose-O-hexoside 1 & [19] \\
\hline 21 & 13.15 & 457.1351 & $\mathrm{C}_{20} \mathrm{H}_{25} \mathrm{O}_{12}$ & $457.1342, \mathbf{1 6 3 . 0 4 0 5 , 1 4 5 . 0 3 0 0 , 1 1 9 . 0 4 9 4}$ & p-coumaric acid-O-pentose-O-hexoside2 & [19] \\
\hline 22 & 13.27 & 457.1352 & $\mathrm{C}_{20} \mathrm{H}_{25} \mathrm{O}_{12}$ & 457.1342,163.0403,119.0496 & $p$-coumaric acid-O-pentose-O-hexoside3 & [19] \\
\hline 23 & 13.69 & 401.1446 & $\mathrm{C}_{18} \mathrm{H}_{25} \mathrm{O}_{10}$ & 401.1446,269.1029,179.0345,161.0448,101.0240 & Unknown 401_13.6 & New \\
\hline 24 & 13.92 & 595.1644 & $\mathrm{C}_{27} \mathrm{H}_{31} \mathrm{O}_{15}$ & $595.1658,459.1141,433.1251,287.0541,169.0142,161.0269,151.0044,135.0444,125.0245$ & Eriodictyol-O-hexose-O-rhamnose isomer1 & {$[18,19,21]$} \\
\hline 25 & 14.06 & 457.1709 & $\mathrm{C}_{21} \mathrm{H}_{29} \mathrm{O}_{11}$ & $457.1703,293.0873,233.0671,149.0464,125.0249,89.0246$ & Unknown 457_14 & New \\
\hline 28 & 14.67 & 421.0763 & $\mathrm{C}_{19} \mathrm{H}_{17} \mathrm{O}_{11}$ & 421.0771,301.0347,331.0458,258.0170 & Isomangiferin & {$[18,19,21]$} \\
\hline 29 & 14.91 & 381.1767 & $\mathrm{C}_{16} \mathrm{H}_{29} \mathrm{O}_{10}$ & $381.1767,249.1344,161.0453,101.0256,96.9703$ & Unknown 381_14.9 & New \\
\hline 30 & 15.15 & 465.1031 & $\mathrm{C}_{21} \mathrm{H}_{21} \mathrm{O}_{12}$ & 465.1046,285.0407,151.0042 & Unknown 465_15.15 & New \\
\hline 31 & 14.33 & 449.1079 & $\mathrm{C}_{21} \mathrm{H}_{21} \mathrm{O}_{11}$ & $449.1081,287.0551,269.0448,259.06616,163.0038,135.0086,121.0290,109.0296$ & Eriodictyol-O-glucoside isomer 1 & [17] \\
\hline 32 & 15.69 & 449.1079 & $\mathrm{C}_{21} \mathrm{H}_{21} \mathrm{O}_{11}$ & $449.1079,287.0553,269.0450,259.0616,225.0561,151.0035,135.0448$ & Eriodictyol-O-glucoside isomer2 & [18] \\
\hline 33 & 15.87 & 579.1725 & $\mathrm{C}_{27} \mathrm{H}_{31} \mathrm{O}_{14}$ & $579.1765,271.0618,151.0027,145.0300,125.0260,119.0489$ & Naringenin-O-hexoside-O-rhamnose isomer1 & [19] \\
\hline 34 & 16.11 & 415.1621 & $\mathrm{C}_{19} \mathrm{H}_{27} \mathrm{O}_{10}$ & $415.1585,273.0681,149.0466,137.0246,101.0249,89.0247$ & Unknown 415_16.1 & New \\
\hline 35 & 16.31 & 579.1701 & $\mathrm{C}_{27} \mathrm{H}_{31} \mathrm{O}_{14}$ & $579.1689,271.0633,151.0022,145.0282,125.0253,119.0500$ & Naringenin-O-hexoside-O-rhamnose isomer2 & [19] \\
\hline 36 & 16.47 & 447.093 & $\mathrm{C}_{21} \mathrm{H}_{19} \mathrm{O}_{11}$ & $447.0956,285.0415,284.0320,255.0299,119.0452,96.9697$ & Orobol/Luteolin-O-hexoside1 & New \\
\hline 37 & 16.63 & 613.1776 & $\mathrm{C}_{27} \mathrm{H}_{33} \mathrm{O}_{16}$ & $613.1766,505.1346,493.1363,433.1129,403.1020,373.0938,331.0838,251.0536,209.0461$ & 3-hydroxyphloretin-3', $5^{\prime}$-di-C-hexoside & [19] \\
\hline 38 & 16.99 & 463.2177 & $\mathrm{C}_{21} \mathrm{H}_{35} \mathrm{O}_{11}$ & 463.2181,251.0763,191.0575,149.0461,96.9692,89.0249 & Unknown 463_17 & New \\
\hline 39 & 17.37 & 463.2186 & $\mathrm{C}_{21} \mathrm{H}_{35} \mathrm{O}_{11}$ & $463.2188,251.0777,191.0567,149.0456,96.9700,89.0250$ & Unknown 463_17.4 & New \\
\hline 40 & 17.55 & 595.1657 & $\mathrm{C}_{27} \mathrm{H}_{31} \mathrm{O}_{15}$ & $595.1658,459.1141,433.1251,287.0541,169.0142,161.0269,151.0044,135.0444,125.0245$ & Eriodictyol-O-hexose-O-rhamnose isomer3 & [19] \\
\hline 41 & 17.59 & 433.1133 & $\mathrm{C}_{21} \mathrm{H}_{21} \mathrm{O}_{10}$ & $433.1153,271.0600,151.0022$ & Naringenin- $O$-hexoside isomer1 & New \\
\hline 42 & 17.88 & 433.1133 & $\mathrm{C}_{21} \mathrm{H}_{21} \mathrm{O}_{10}$ & $433.1153,271.0600,151.0022$ & Naringenin-O-hexoside isomer2 & New \\
\hline 43 & 18.18 & 593.1505 & $\mathrm{C}_{27} \mathrm{H}_{29} \mathrm{O}_{15}$ & $593.1522,285.0408$ & ${ }^{*}$ Luteolin-O-rutinoside (Scolymoside) & {$[18,19]$} \\
\hline 44 & 18.28 & 487.1812 & $\mathrm{C}_{22} \mathrm{H}_{31} \mathrm{O}_{12}$ & 487.1812,191.0563,149.0456,101.0245,89.0247 & Unknown 487_18.3 & New \\
\hline 45 & 18.47 & 597.1815 & $\mathrm{C}_{27} \mathrm{H}_{33} \mathrm{O}_{15}$ & $597.1801,477.1390,417.1172,387.1068,357.0969,209.0449,167.0363,125.0236$ & Phloretin-3',5'-di-C-glucoside & [19] \\
\hline
\end{tabular}


Table 1. Cont.

\begin{tabular}{|c|c|c|c|c|c|c|}
\hline & Retention Time & Exprimental $\mathrm{m} / \mathrm{z}$ & Formula & $\mathrm{MS}^{\mathrm{E}}$ Fragments & & Reference \\
\hline 46 & 18.59 & 433.1129 & $\mathrm{C}_{21} \mathrm{H}_{21} \mathrm{O}_{10}$ & $433.1133,271.0607,135.0452,91.0191$ & Naringenin-O-hexoside isomer3 & New \\
\hline 47 & 18.73 & 447.0942 & $\mathrm{C}_{21} \mathrm{H}_{19} \mathrm{O}_{11}$ & $447.0956,285.0414,284.0334$ & Orobol/Kaempferol/Luteolin-O-hexoside2 & New \\
\hline 48 & 19.34 & 595.1661 & $\mathrm{C}_{27} \mathrm{H}_{31} \mathrm{O}_{15}$ & $595.1654,459.1166,287.0532,161.0247,151.0033,135.0462,125.0247$ & Eriodictyol-O-hexose-O-rhamnose isomer4 & [19] \\
\hline 49 & 19.53 & 579.1732 & $\mathrm{C}_{27} \mathrm{H}_{31} \mathrm{O}_{14}$ & $579.1657,271.0623,151.0035,145.0300,125.0260,119.0486,96.9697$ & Naringenin-O-hexoside-O-rhamnose isomer3/Narirutin & [21] \\
\hline 50 & 19.83 & 417.1176 & $\mathrm{C}_{21} \mathrm{H}_{21} \mathrm{O}_{9}$ & $417.1171,211.0763,169.0662,98.0241$ & Unknown 417_19.8 isomer1 & New \\
\hline 52 & 20.77 & 609.1811 & $\mathrm{C}_{28} \mathrm{H}_{33} \mathrm{O}_{15}$ & $609.1781,301.0717,286.0483$ & ${ }^{*}$ Hesperidin (Hesperetin-O-rutinoside) & [18] \\
\hline 53 & 20.74 & 579.1681 & $\mathrm{C}_{27} \mathrm{H}_{31} \mathrm{O}_{14}$ & $579.1765,271.0617,151.0031,145.0292,125.0250,119.0492,96.9690$ & Naringenin-O-hexoside-O-rhamnose isomer4 & [19] \\
\hline 54 & 20.99 & 527.1194 & $\mathrm{C}_{26} \mathrm{H}_{23} \mathrm{O}_{12}$ & $527.1194,317.0669,287.0562,245.0457,193.0141$ & Unknown 527_20.99 & New \\
\hline 55 & 21 & 593.2447 & $\mathrm{C}_{26} \mathrm{H}_{41} \mathrm{O}_{15}$ & $547.2388,515.2121,96.9693$ & Unknown 593_21 & New \\
\hline 56 & 21.16 & 271.0612 & $\mathrm{C}_{15} \mathrm{H}_{11} \mathrm{O}_{5}$ & 271.0612,135.0449,96.9697, 91.0187 & Butein/Butin & [15] \\
\hline 57 & 21.3 & 549.1619 & $\mathrm{C}_{26} \mathrm{H}_{29} \mathrm{O}_{13}$ & $549.1622,301.0710,255.0663,237.0594,211.0773,125.0275,89.0239$ & Unknown 549_21.3 & New \\
\hline 60 & 22.3 & 417.1193 & $\mathrm{C}_{21} \mathrm{H}_{21} \mathrm{O}_{9}$ & 417.1171,211.0763,169.0662,98.0241 & Unknown 417_22.3 isomer2 & New \\
\hline 61 & 23.49 & 433.1147 & $\mathrm{C}_{21} \mathrm{H}_{21} \mathrm{O}_{10}$ & $433.1145,271.0619,135.0456,91.0194$ & Butein-hexoside isomer2 & New \\
\hline 62 & 24.39 & 285.0359 & $\mathrm{C}_{15} \mathrm{H}_{9} \mathrm{O}_{6}$ & $285.0404,161.0290,151.0016,135.0422$ & Orobol & {$[15,16]$} \\
\hline 63 & 24.4 & 287.0561 & $\mathrm{C}_{15} \mathrm{H}_{11} \mathrm{O}_{6}$ & 287.0561,151.0038,135.0452 & Eriodictyol & [26] \\
\hline 64 & 24.7 & 593.1856 & $\mathrm{C}_{28} \mathrm{H}_{33} \mathrm{O}_{14}$ & $593.1882,285.0759,243.0666,151.0045$ & Didymin/Neoponcirin (Isosakuranetin-7-O-rutinoside) & New \\
\hline 65 & 24.79 & 447.2226 & $\mathrm{C}_{21} \mathrm{H}_{35} \mathrm{O}_{10}$ & $447.2246,315.1848,161.0459,101.0243,96.9688,113.0239,71.0130$ & Unknown 447_25 & New \\
\hline 66 & 25.03 & 285.0402 & $\mathrm{C}_{15} \mathrm{H}_{9} \mathrm{O}_{6}$ & $\mathbf{2 8 5 . 0 4 0 4 , 1 7 5 . 0 3 9 6 , 1 5 1 . 0 0 5 1 , 1 3 3 . 0 3 0 1}$ & *Luteolin & [25] \\
\hline 67 & 25.35 & 285.0783 & $\mathrm{C}_{16} \mathrm{H}_{13} \mathrm{O}_{5}$ & $285.0400,255.0698,163.0379,135.0315$ & Unknown 285_25.35 & New \\
\hline 68 & 25.93 & 301.2021 & $\mathrm{C}_{16} \mathrm{H}_{29} \mathrm{O}_{5}$ & 301.2024,96.9695 & Unknown 301_25.9 & New \\
\hline 69 & 26.36 & 271.0609 & $\mathrm{C}_{15} \mathrm{H}_{11} \mathrm{O}_{5}$ & $271.0620,151.0036,119.0500,107.0136,96.9683$ & ${ }^{*}$ Naringenin & [26] \\
\hline 70 & 27.05 & 327.217 & $\mathrm{C}_{18} \mathrm{H}_{31} \mathrm{O}_{5}$ & 327.2184,229.1416,211.1331,171.1022 & Unknown 327_27 & New \\
\hline 71 & 27.23 & 301.0713 & $\mathrm{C}_{16} \mathrm{H}_{13} \mathrm{O}_{6}$ & 301.0712,286.0497,164.0111,151.0034,136.0181 & ${ }^{*}$ Hesperetin & {$[15,26]$} \\
\hline 74 & 30.15 & 285.0763 & $\mathrm{C}_{16} \mathrm{H}_{13} \mathrm{O}_{5}$ & $285.0760,270.0516,243.0666,164.0114,151.0030,136.0164,108.0216$ & (Iso)sakuranetin & [14] \\
\hline
\end{tabular}

*Standard was use to confirm retention time and spectra, base peaks in $\mathrm{MS}^{\mathrm{E}}$ fragmentation data in bold. 
Figure 4 contains the structures of selected compounds presented in Table 1. The PCA cluster map of all the samples is presented in Figure 5. Two Cyclopia species that do not produce mangiferin (C. buxifolia, BX and C. bowieana, BW) are seen as outliers on the right hand side. The clustering was driven by mangiferin and the rest of the species were not visually well separated in the cluster map. In addition, the samples from flower parts other than the leaves (twigs, stems and flowers), also influenced the separation. Figure 6 is the cluster map of only the leaf samples with the mangiferin data excluded. The groupings of the species in clusters improved somewhat with e.g. C. genistoides now clustering on its own. In Figure 7 only the leaf extracts of the three commercial species C. intermedia (IN), C. genistoides (GE), and C. subternata (SU) were investigated with citric acid and mangiferin excluded. This showed a separation of $C$. genistoides (green, cluster 2,5, and 6) from C. subternata (orange, cluster 1) and C. intermedia (red, cluster 3,4), with some extracts forming additional clusters that appear to be based on geography/provenance/population.
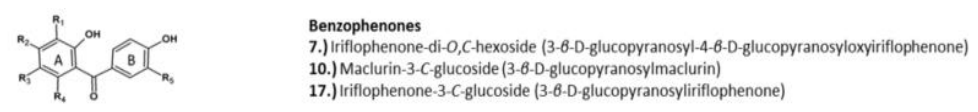

\section{(20)}



Xanthones
12.) Mangiferin-O-hexoside

12.) Isomangiferin- $O$-hexoside

26.) Mangiferin

28.) Isomangiferin

$R_{1}=H ; R_{2}$ or $R_{4}=O$-hexosyl; $R_{3}=C$-glucosyl

$R_{1}=C$-glucosyl; $R_{2}$ or $R_{4}=O$-hexosyl; $R_{3}=$ H

$R_{1}=H ; R_{2}=R_{4}=O H ; R_{3}=C-$-glucosy

$R_{1}=C$-glucosyl; $R_{2}=R_{4}=O H ; R_{3}=H$

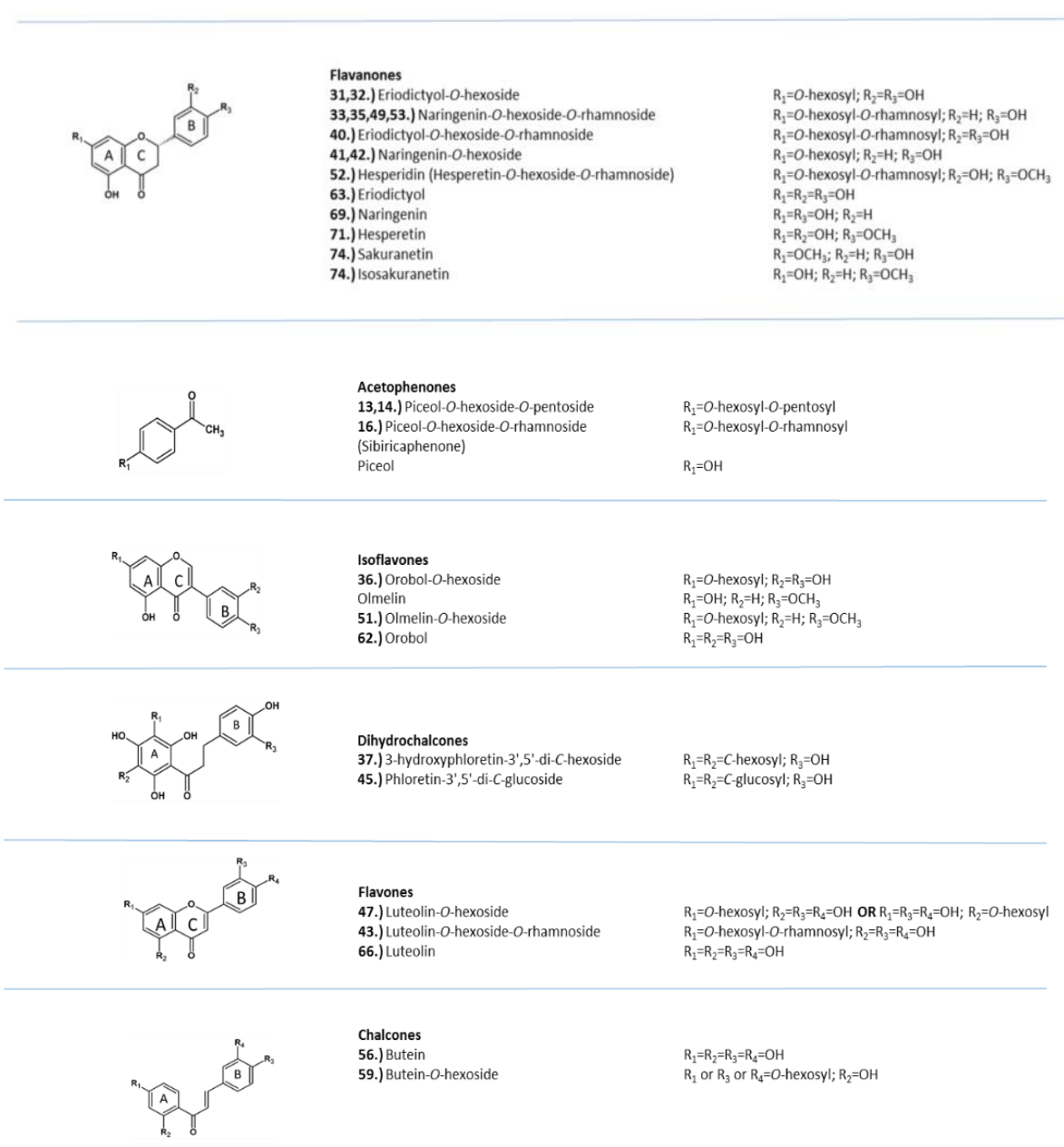

Figure 4. Selected structures of the compounds detected in Cyclopia extracts, numbered according to Table 1. 


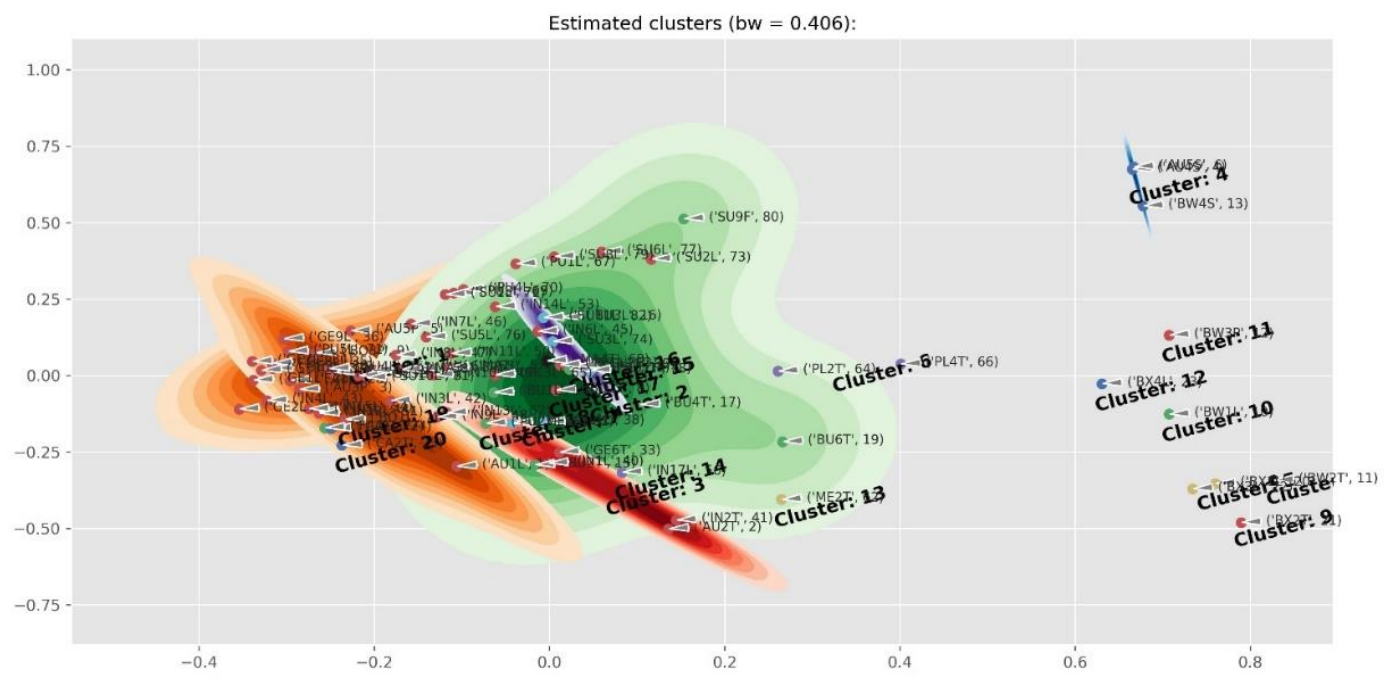

Figure 5. Cluster map showing the two Cyclopia species that apparently do not produce mangiferin (C. buxifolia, BX and C. bowieana, BW) as outliers on the right hand side. C. aurescens (AU), C. bolusii (BO), C. bowiena (BW), C. burtonii (BU), C. buxifolia (BX), C. capensis (CA), C. falcata (FA), C. genistoides (GE), C. glabra (GL), C. intermedia (IN), C. maculata (MA), C. meyeriana (ME), C. plicata (PL), C. pubescens (PU) and C. subternata (SU).

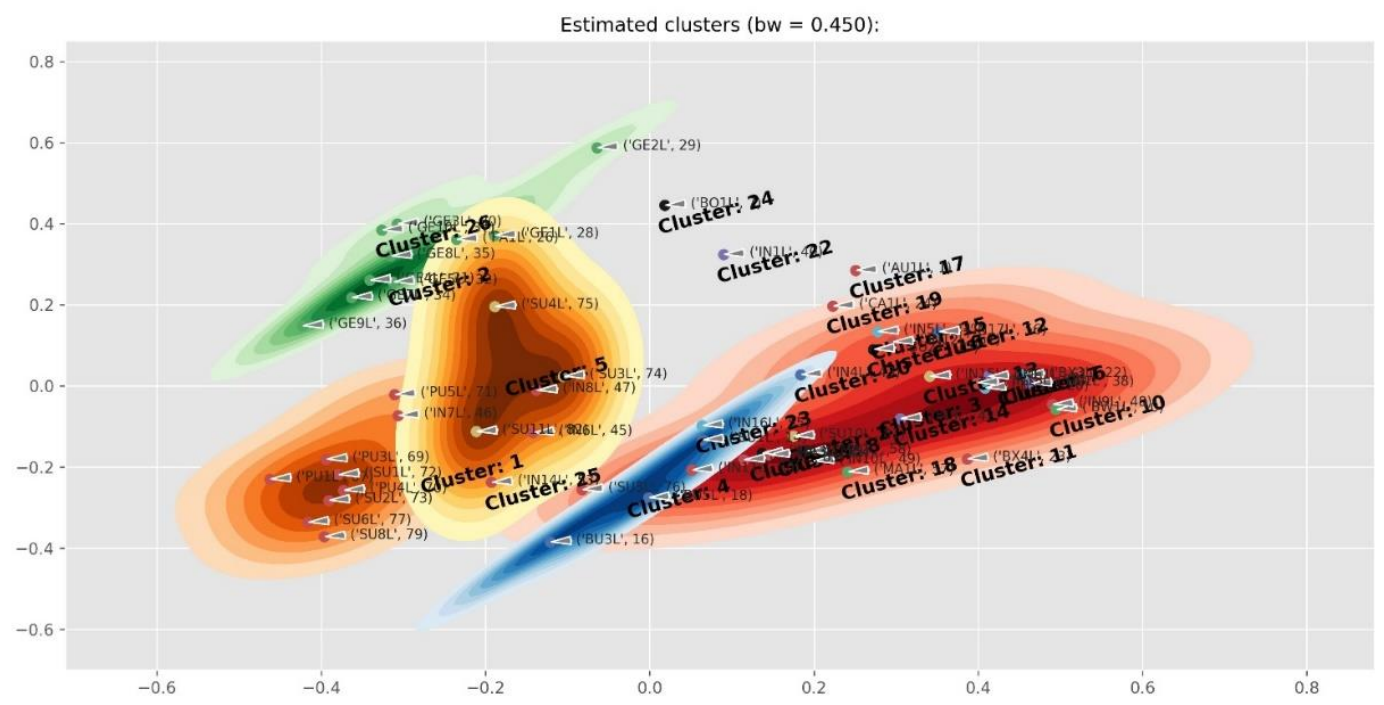

Figure 6. Cluster map of only the leaf samples of Cyclopia species with mangiferin excluded, showing an improved separation of the main cluster in Figure 5. Note, for example, that the C. genistoides samples now form a cluster 2 (shown in green). C. aurescens (AU), C. bolusii (BO), C. bowiena (BW), C. burtonii (BU), C. buxifolia (BX), C. capensis (CA), C. falcata (FA), C. genistoides (GE), C. glabra (GL), C. intermedia (IN), C. maculata (MA), C. meyeriana (ME), C. plicata (PL), C. pubescens (PU) and C. subternata (SU). 


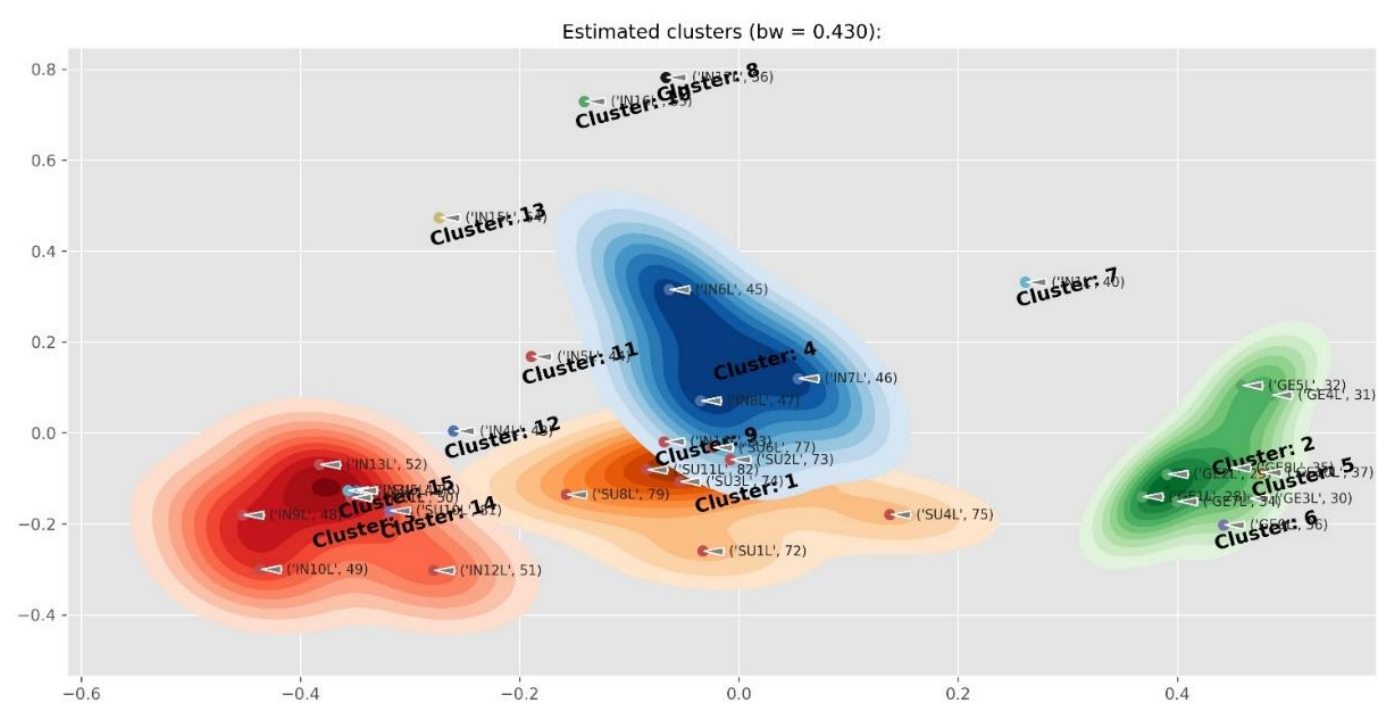

Figure 7. Cluster map of the Cyclopia intermedia (IN), C. genistoides (GE), and C. subternata (SU) leaf extracts with mangiferin and citric acid excluded, showing a separation of $C$. genistoides (green, cluster 2,5, and 6) and from C. subternata (orange, cluster 1) and C. intermedia (red, cluster 3,4) with some extracts forming additional clusters that appear to be based on geography/provenance/population.

\subsection{Old Samples Versus Contemporary Samples}

No significant differences between older and newer sample were detected which confirms the stability of these phenolic compounds in plants if stored as dry material.

\subsection{Differences Between Plant Parts (Twigs, Leaves, Pods, Flowers And Seeds)}

This study has shown that the same compounds occur at varying concentrations in different plant parts, with the exception of the seeds that contain certain unique compounds but lack others, especially the flavonoid glycosides (Figure 8). A comparison of the main classes of compounds between plants parts is presented in Figure 9. There are only quantitative differences between twigs, leaves and pods in Cyclopia aurescens Kies, but the seeds are markedly different, with a dominance of chalcones and flavanones. The major seed flavonoids in Cyclopia were reported by De Nysschen et al. [15] as butin, 3'-hydroxydaidzein, butein and vicenin-2, but these compounds have not been detected in more recent studies. In our study, butein/butin and derivatives were detected in seeds at much higher levels than in the leaves, pods or stems. We have recorded a significant peak for 3 'hydroxydaidzein (one of the main compounds detected in seeds by De Nysschen $[14,15]$ in one of the seed samples (AU5S, Cyclopia aurescens Kies). This peak corresponds to 3'hydroxydaidzein ( $m / z 269.0451, \mathrm{C}_{15} \mathrm{H}_{9} \mathrm{O}_{5}$ fragment ions: 269.0453 (base peak), 133.0294, retention time 20.9, eluting just before the butein peak in Figure 8). Vicenin-2 is also more prominent in the seed samples, but co-elutes with isomangiferin in the extracts from twigs, leaves, pods and flowers. 


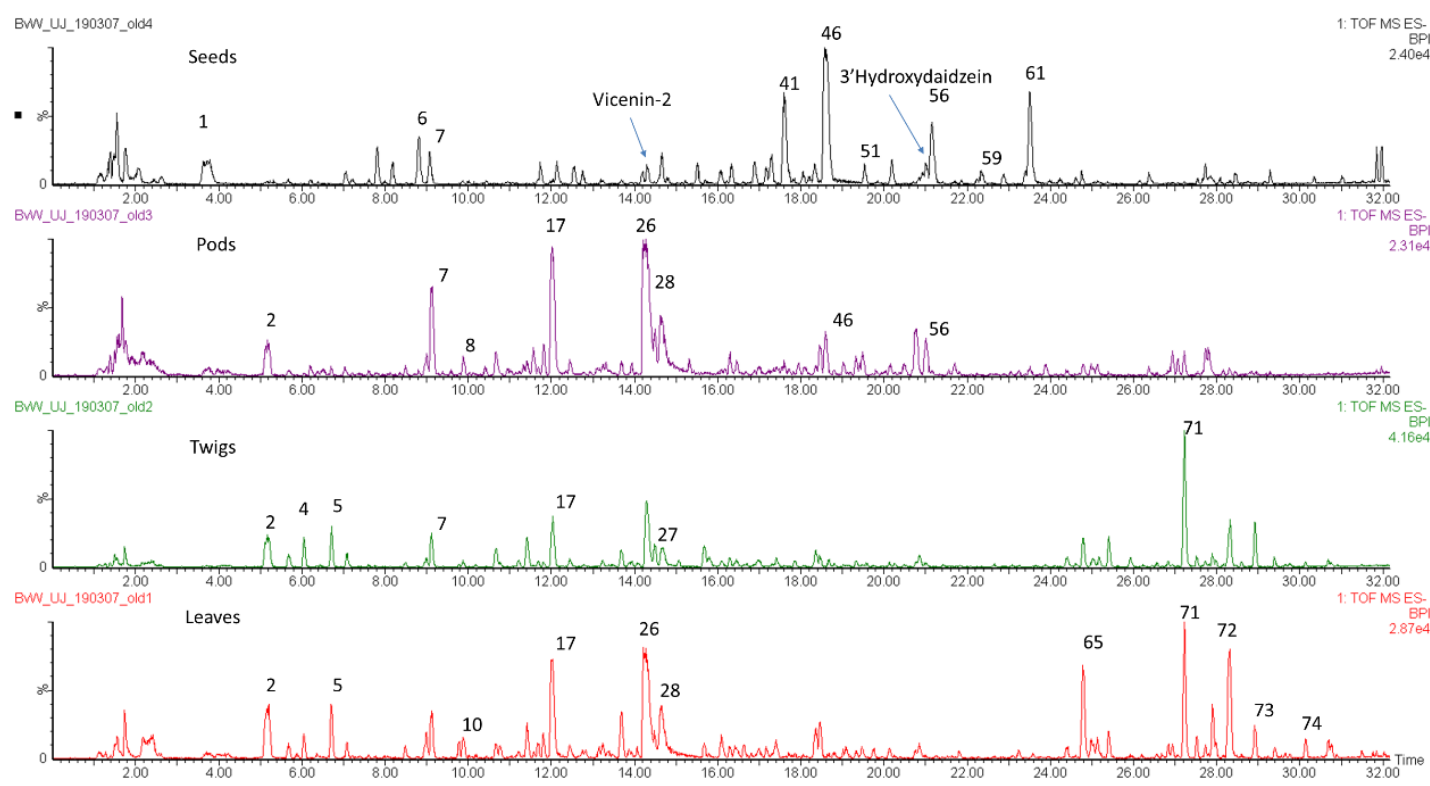

Figure 8. Total ion chromatograms of different plant parts of Cyclopia aurescens Kies, showing the seed extract on top with low levels of mangiferin and isomangiferin (compounds $\mathbf{2 6}$ and 28) and large peaks for compounds 46 (naringenin-O-hexoside isomer 3), 56 (butein) and 61 (butein-hexoside isomer 2).



Figure 9. Composition of classes of compounds (as a sum of the concentrations in $\mathrm{mg} / \mathrm{kg}$ ) in various plant parts of Cyclopia aurescens (AU1-5, all from Klein Swartberg, refer to Table 2) (L = leaves, T = twigs, $\mathrm{P}=$ pods, $\mathrm{S}=$ seeds). Leaves, twigs and pods are chemically diverse and have a similar combination of compounds whilst the seeds contain mainly chalcones and flavanones.

\subsection{Diagnostic Value of Phenolic Compounds}

The results suggest that phenolic compounds do have diagnostic value in distinguishing between some of the species, especially when combinations of some of the compounds are used. Figure 10 shows the average composition of compounds for the species studied. Cyclopia buxifolia and C. bowieana are apparently unique in their inability to produce xanthones and benzophenones; this chemical difference presumably makes them unsuitable for tea production. The other species have similar combinations of compounds, but the relatively high levels of xanthones in C. genistoides must be noted. The seemingly random quantitative combinations of main compounds in leaf samples of all the species are shown in Figure 11 comparing the concentrations of the individual flavanones. There is visually no clear pattern in Figure 11 and the underlying processes (phenotypic or genetic) deserve more detailed studies. 
A somewhat clearer picture emerges when multiple samples from different provenances are analysed, as shown in Figure 12 that represents flavanones of the commercial species: C. genistoides, C. intermedia and C. subternata. Note that different plants collected from the same population often have very similar chemical profiles, while different populations tend to be somewhat different. From this result it is clear that a large part of the chemical variation in the three commercial species can be ascribed to provenance. Chemical differences at population level are often genetically determined and it will be interesting to compare cultivated plants with plants from the original populations where the seeds were collected. A similar pattern emerges when the phenolic compounds from the loading plots that caused the separation of clusters in Figure 7 are considered (Figure 13). Note that the unique combinations of compounds that are uniform within a provenance are often discontinuous between all or most of the species. The chemical identities and the diagnostic value of the nine compounds shown in Figure 13 should be a priority for future studies. This would require isolation and purifying the compounds and confirmation and structural elucidation using Nuclear Magnetic Resonance spectroscopy (NMR).

When mangiferin and citric acid were removed from the data set, distinct clusters were obtained. Cluster analysis, however, often grouped extracts from the same species together but many were not congruent with species delimitations, i.e. clustering was based on provenance rather than species (see Figure S2 in Supplementary-the Dendrogram). The dendrogram also did not group species together that are presumed to be related on the basis of morphological characters. Cyclopia genistoides differs from C. subternata and the majority of provenances of $C$. intermedia in the higher concentrations of mangiferin. Cyclopia intermedia is a widely distributed species with some morphological differences between populations and it seems that some outlier values may obscure what is otherwise a promising diagnostic difference. Stepanova et al. [24] found leaf anatomical characters to distinguish between C. genistoides, C. intermedia and C. subternata but chemical analyses are clearly a more practical approach for quality control purposes. Particular provenances are usually selected for crop development, so that commercial tea samples are likely to be chemically more uniform than wild-harvested material collected from unknown populations. Developers often try to standardise the chemical composition of herbal products in order to minimize batch to batch variation. In this context, the numerous chemical compounds and their diversity in Cyclopia species described here are likely to provide a practical and reproducible approach to identify the source species of the material, to detect possible contaminants and assess the quality of the product.

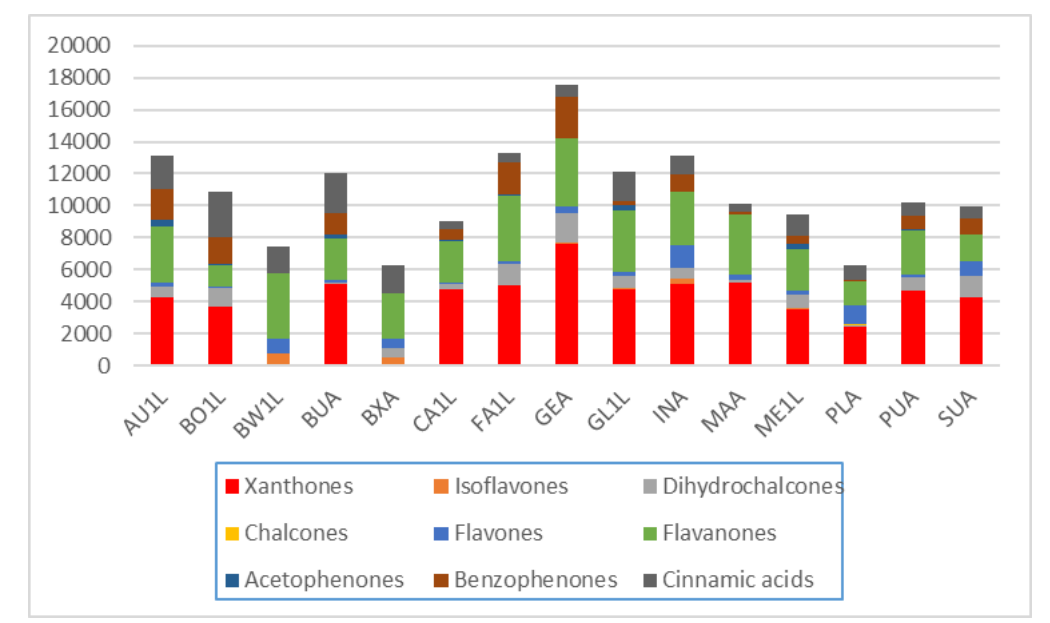

Figure 10. Average levels ( $\mathrm{mg} / \mathrm{kg}$ relative to mangiferin) of nine classes of phenolic compounds in leaf samples of 15 species of Cyclopia. The A at the end of the species codes means that it is an average value for all the leaf samples of that species analysed-see Table 2). C. aurescens (AU), C. bolusii (BO), C. bowiena (BW), C. burtonii (BU), C. buxifolia (BX), C. capensis (CA), C. falcata (FA), C. genistoides (GE), C. glabra (GL), C. intermedia (IN), C. maculata (MA), C. meyeriana (ME), C. plicata (PL), C. pubescens (PU) and C. subternata (SU). 


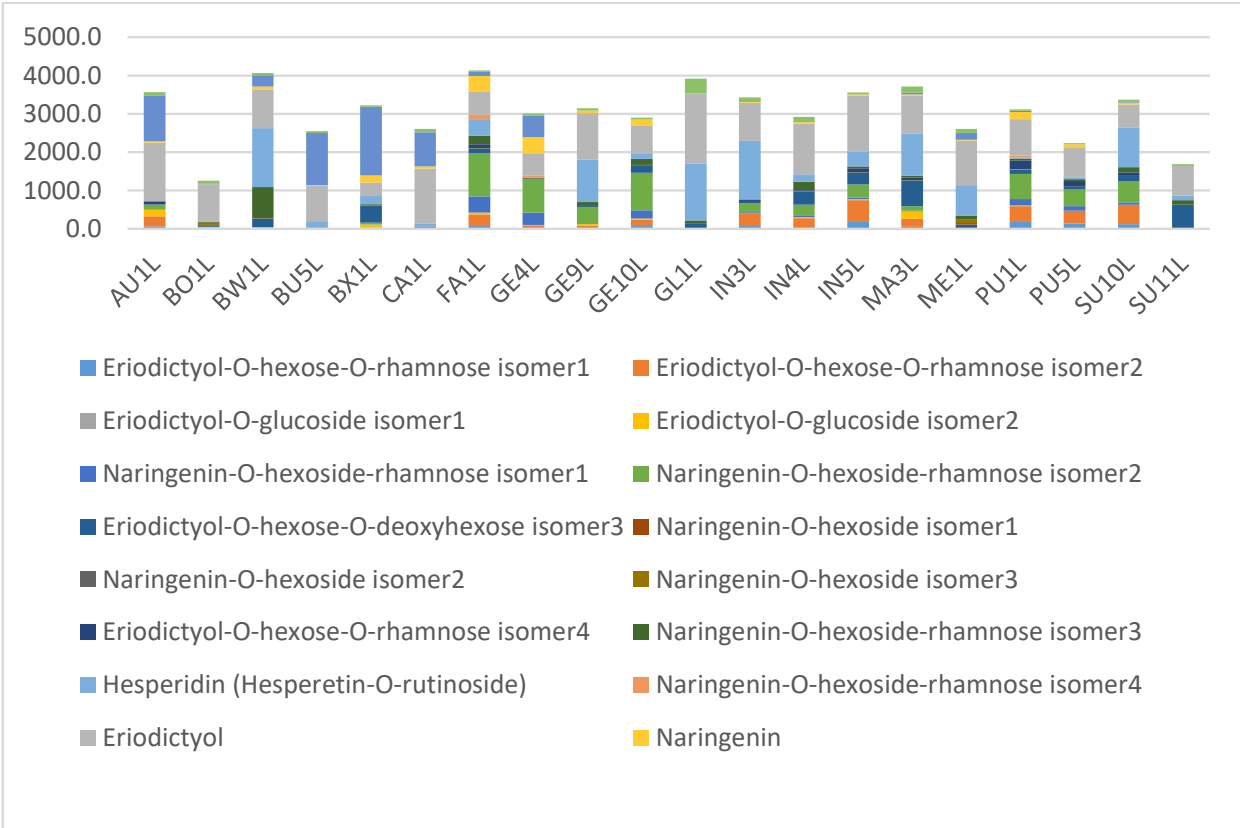

Figure 11. Composition of the flavanones in the leaf (L) samples in the different Cyclopia species in $\mathrm{mg} / \mathrm{kg}$ relative to mangiferin. For sample codes see Table 2). C. aurescens (AU), C. bolusii (BO), C. bowiena (BW), C. burtonii (BU), C. buxifolia (BX), C. capensis (CA), C. falcata (FA), C. genistoides (GE), C. glabra (GL), C. intermedia (IN), C. maculata (MA), C. meyeriana (ME), C. plicata (PL), C. pubescens (PU) and C. subternata (SU).



Figure 12. Composition of the flavanones ( $\mathrm{mg} / \mathrm{kg}$ relative to mangiferin) in the leaf samples from the three main commercial sources of honeybush tea: Cyclopia genistoides (GE, nine samples), C. intermedia (IN, 16 samples) and C. subternata (SU, nine samples). For sample codes see Table 2. Numbering is according to the collection point and from West to East in each species. 


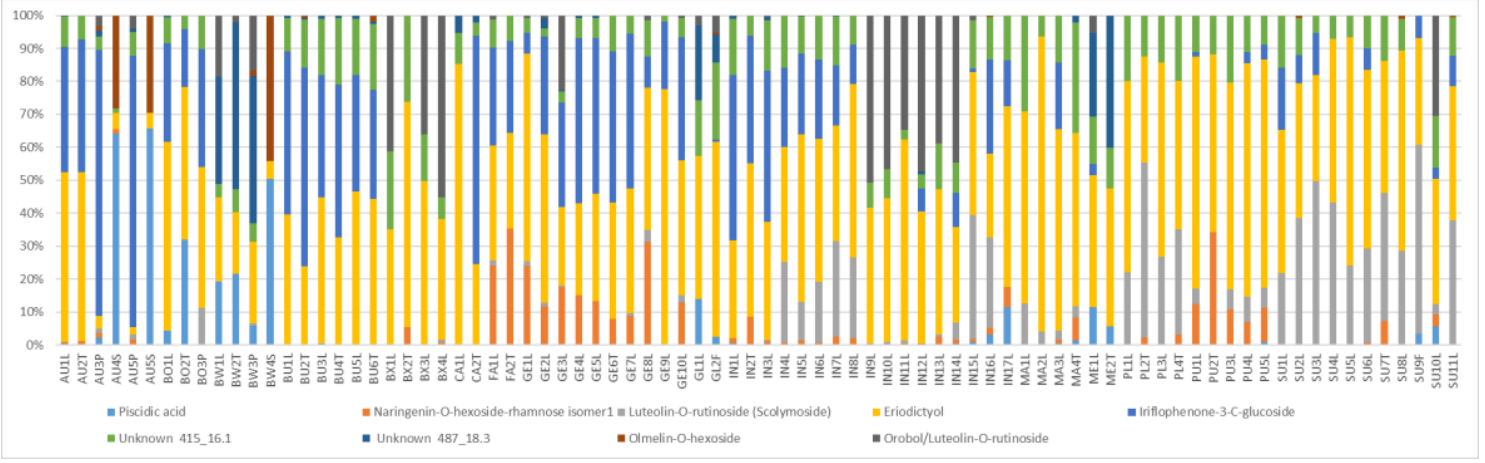

Figure 13. Composition of phenolic compounds relative to the total from the loading plots that caused the separation of clusters (see Figure 7). For sample codes see Table 2, Cyclopia aurescens (AU), C. bolusii (BO), C. bowiena (BW), C. burtonii (BU), C. buxifolia (BX), C. capensis (CA), C. falcata (FA), C. genistoides (GE), C. glabra (GL), C. intermedia (IN), C. maculata (MA), C. meyeriana (ME), C. plicata (PL), C. pubescens (PU) and C. subternata (SU); twigs (T), leaves (L), flowers (F) and pods (P). Numbering is according to the collection point and from West to East in each species.

\section{Conclusions}

The analyses of Cyclopia species using UPLC-HRMS with simultaneous collection of low collision energy MS data, ramped collision energy MS data and UV data resulted in large, complex datasets, which revealed considerable complexity in the phenolic compounds observed. MS ${ }^{\mathrm{E}}$ fragmentation data is presented for 74 phenolic compounds, including at least three benzophenones, two dihydrochalcones, three chalcones, three xanthones, 17 flavanones, three flavones, two isoflavones, three acetophenones and eight phenolic acids (cinnamic acid derivatives). Some unknown compounds have been tentatively identified including piceol-hexose-pentoside isomers, piceol-hexose-rhamnoside, butein-hexosides and olmelin-O-hexoside.

The study also revealed that the methods of extraction and analysis by UPLC-HRMS analysis influence the results and that both polar and nonpolar (methylated) compounds may be overlooked in routine analyses. Plant parts (twigs, leaves, flowers and pods) show only quantitative differences in the main constituents but seeds often contain much lower concentrations of xanthones and higher concentrations of chalcones and other flavonoids. As suggested in the literature, phenolic compounds have limited chemosystematic value at species level but a combination of chemical characters can be used to distinguish between some of the species. The study provides deeper insights into the chemical complexity of Cyclopia species and the potential role that UPLC-HRMS analyses can play, not only in quality control but also to help select superior chemotypes for crop and product development.

\section{Materials and Methods}

Methods and equipment were the same as used by Stander et al., [25] but the gradient was extended to 37 minutes to accommodate more non-polar compound including isoflavones and methoxylated flavonoids described in previous papers [14,17].

Table 2. A list of the samples, their species, sample codes, voucher numbers, collection dates and localities, numbered from West to East per species.

\begin{tabular}{|c|c|c|c|c|c|c|}
\hline $\begin{array}{l}\text { Sample } \\
\text { Number }\end{array}$ & Species & Sample Code & Provenance & $\begin{array}{l}\text { VOUCHER } \\
\text { SPECIMEN }\end{array}$ & $\begin{array}{c}\text { Date } \\
\text { Collected }\end{array}$ & $\begin{array}{c}\text { Part(s) } \\
\text { Analysed }\end{array}$ \\
\hline 1 & \multirow{5}{*}{ Cyclopia aurescens Kies } & AU1L & Klein Swartberg & Schutte \& Van Wyk 771a & 3/2/1992 & leaves \\
\hline 2 & & AU2T & Klein Swartberg & Schutte \& Van Wyk 771a & $3 / 2 / 1992$ & twigs \\
\hline 3 & & AU3P & Klein Swartberg & Schutte \& Van Wyk 771a & $3 / 2 / 1992$ & pods \\
\hline 4 & & AU4S & Klein Swartberg & Schutte \& Van Wyk 771a & $3 / 2 / 1992$ & seeds \\
\hline 5 & & AU5P & Klein Swartberg & Schutte \& Van Wyk 775 & 3/2/1992 & pods \\
\hline
\end{tabular}


Table 2. Cont

\begin{tabular}{|c|c|c|c|c|c|c|}
\hline $\begin{array}{l}\text { Sample } \\
\text { Number }\end{array}$ & Species & Sample Code & Provenance & $\begin{array}{l}\text { VOUCHER } \\
\text { SPECIMEN }\end{array}$ & $\begin{array}{c}\text { Date } \\
\text { Collected }\end{array}$ & $\begin{array}{c}\text { Part(s) } \\
\text { Analysed }\end{array}$ \\
\hline 6 & & AU5S & Klein Swartberg & Schutte \& Van Wyk 775 & 3/2/1992 & seeds \\
\hline 7 & \multirow{3}{*}{$\begin{array}{c}\text { Cyclopia bolusii Hofmeyr \& } \\
\text { E.Phillips }\end{array}$} & BO1L & Swartberg Pass & Schutte \& Vlok 749 & 1/2/1992 & leaves \\
\hline 8 & & $\mathrm{BO} 2 \mathrm{~T}$ & Swartberg Pass & Schutte \& Vlok 749 & $1 / 2 / 1992$ & twigs \\
\hline 9 & & $\mathrm{BO} 3 \mathrm{P}$ & Swartberg Pass & Schutte \& Vlok 749 & $1 / 2 / 1992$ & pods \\
\hline 10 & \multirow{4}{*}{ Cyclopia bowieana Harv. } & BW1L & Ruitersberg & Schutte 526 & $1 / 1990$ & leaves \\
\hline 11 & & BW2T & Ruitersberg & Schutte 526 & $1 / 1990$ & twigs \\
\hline 12 & & BW3P & Ruitersberg & Schutte 526 & $1 / 1990$ & pods \\
\hline 13 & & BW4S & Ruitersberg & Schutte 526 & $1 / 1990$ & seeds \\
\hline 14 & \multirow{6}{*}{$\begin{array}{c}\text { Cyclopia burtonii Hofmeyr \& } \\
\text { E.Phillips }\end{array}$} & BU1L & Swartberg & Schutte 641 & 9/1990 & leaves \\
\hline 15 & & BU2T & Swartberg & Schutte 641 & 9/1990 & twigs \\
\hline 16 & & BU3L & Swartberg Pass & Schutte 643 & 9/1990 & leaves \\
\hline 17 & & BU4T & Swartberg Pass & Schutte 643 & 9/1990 & twigs \\
\hline 18 & & BU5L & Swartberg Pass & Schutte 747 & $1 / 2 / 1992$ & leaves \\
\hline 19 & & BU6T & Swartberg Pass & Schutte 747 & $1 / 2 / 1992$ & twigs \\
\hline 20 & \multirow{4}{*}{$\begin{array}{c}\text { Cyclopia buxifolia (Burm.f.) } \\
\text { Kies }\end{array}$} & BX1L & Jonkershoek & Schutte 604 & 9/1990 & leaves \\
\hline 21 & & BX2T & Jonkershoek & Schutte 604 & 9/1990 & twigs \\
\hline 22 & & BX3L & Jonkershoek & Schutte 605 & 9/1990 & leaves \\
\hline 23 & & BX4L & Jonkershoek & Schutte 606 & 9/1990 & leaves \\
\hline 24 & \multirow{2}{*}{ Cyclopia capensis T.M.Salter } & CA1L & Cape Point & Schutte 550 & $1 / 1990$ & Leaves \\
\hline 25 & & CA2T & Cape Point & Schutte 550 & $1 / 1990$ & twigs \\
\hline 26 & \multirow{2}{*}{ Cyclopia falcata (Harv.) Kies } & FA1L & Franschoek Pass & Schutte 612 & 9/1990 & leaves \\
\hline 27 & & FA2T & Franschhoek Pass & Schutte 612 & 9/1990 & twigs \\
\hline 28 & \multirow{10}{*}{ Cyclopia genistoides (L.) R.Br. } & GE1L & $\begin{array}{l}\text { Constantia } \\
\text { Mountain }\end{array}$ & Schutte 615 & $14 / 09 / 1990$ & leaves \\
\hline 29 & & GE2L & $\begin{array}{l}\text { Constantia } \\
\text { Mountain }\end{array}$ & Van Wyk 2747 & $16 / 1 / 1988$ & leaves \\
\hline 30 & & GE3L & Rooiels & Schutte 622 & $15 / 9 / 1990$ & leaves \\
\hline 31 & & GE4L & Bettys Bay & Schutte 624 & $15 / 9 / 1990$ & leaves \\
\hline 32 & & GE5L & Bettys Bay & Schutte 624 & $15 / 9 / 1990$ & leaves \\
\hline 33 & & GE6T & Bettys Bay & Schutte 624 & $15 / 9 / 1990$ & twigs \\
\hline 34 & & GE7L & Bettys Bay & Schutte 624 & $15 / 9 / 1990$ & leaves \\
\hline 35 & & GE8L & Bettys Bay & Schutte 625 & $15 / 9 / 1990$ & leaves \\
\hline 36 & & GE9L & $\begin{array}{l}\text { Buffelshoek, } \\
\text { Albertinia }\end{array}$ & Vlok 2249 & 28/11/1989 & leaves \\
\hline 37 & & GE10L & De Hoop & Boatwright \& Magee 53 & $25 / 11 / 2004$ & leaves \\
\hline 38 & \multirow{2}{*}{$\begin{array}{l}\text { Cyclopia glabra (Hofmeyr \& } \\
\text { E.Phillips) A.L. Schutte }\end{array}$} & GL1L & Matroosberg & Schutte 557 & $01 / 2 / 1990$ & leaves \\
\hline 39 & & GL2F & Matroosberg & Schutte 557 & $01 / 2 / 1990$ & flowers \\
\hline 40 & & IN1L & Anysberg & Schutte 680 & 9/1990 & leaves \\
\hline 41 & Cyclopia intermedia E.Mey. & IN2T & Anysberg & Schutte 680 & 9/1990 & twigs \\
\hline 42 & & IN3L & Touwsberg & $\begin{array}{c}\text { Van Wyk, Winter \& } \\
\text { Tilney } 3416\end{array}$ & 05/10/1993 & leaves \\
\hline 43 & & IN4L & Oudtshoorn & Schutte 521 & $24 / 1 / 1990$ & leaves \\
\hline 44 & & IN5L & Teeberg & Schutte 524 & 25/1/1990 & leaves \\
\hline 45 & & IN6L & Teeberg & Schutte $724 b \mathcal{E} c$ & $1 / 1992$ & leaves \\
\hline 46 & & IN7L & Swartberg Pass & Schutte 646 & $17 / 9 / 1990$ & leaves \\
\hline 47 & & IN8L & Swartberg Pass & Schutte 647 & $17 / 9 / 1990$ & leaves \\
\hline 48 & & IN9L & $\begin{array}{l}\text { Prince Alfred's } \\
\text { Pass } \\
\end{array}$ & Van Wyk 928 & 20/2/1982 & leaves \\
\hline 49 & & IN10L & $\begin{array}{l}\text { Prince Alfred's } \\
\text { Pass }\end{array}$ & Schutte 578 & 23/1/1990 & leaves \\
\hline 50 & & IN11L & K'Buku, De Vlug & Van Wyk 945 & 20/2/1982 & leaves \\
\hline 51 & & IN12L & K'Buku, De Vlug & Van Wyk 947 & 20/2/1982 & leaves \\
\hline 52 & & IN13L & K'Buku, De Vlug & Van Wyk 951 & 20/2/1982 & leaves \\
\hline 53 & & IN14L & Joubertina & Schutte 507 & $22 / 01 / 1990$ & leaves \\
\hline 54 & & IN15L & Hoopsberg & Schutte 513 & 23/01/1990 & leaves \\
\hline 55 & & IN16L & Hoopsberg & Schutte 573 & $1 / 1990$ & leaves \\
\hline 56 & & IN17L & Hoopsberg & Schutte 573 & $1 / 1990$ & twigs \\
\hline
\end{tabular}


Table 2. Cont.

\begin{tabular}{|c|c|c|c|c|c|c|}
\hline $\begin{array}{l}\text { Sample } \\
\text { Number }\end{array}$ & Species & Sample Code & Provenance & $\begin{array}{l}\text { VOUCHER } \\
\text { SPECIMEN }\end{array}$ & $\begin{array}{c}\text { Date } \\
\text { Collected }\end{array}$ & $\begin{array}{c}\text { Part(s) } \\
\text { Analysed }\end{array}$ \\
\hline 57 & \multirow{4}{*}{$\begin{array}{c}\text { Cyclopia maculata (Andrews) } \\
\text { Kies }\end{array}$} & MA1L & Garcia State Forest & Schutte $528 b$ & $26 / 01 / 1990$ & leaves \\
\hline 58 & & MA2L & Garcia State Forest & Van Wyk 895 & $02 / 10 / 1981$ & leaves \\
\hline 59 & & MA3L & Garcia State Forest & Schutte 528 & $1 / 1990$ & leaves \\
\hline 60 & & MA4T & Garcia State Forest & Schutte 528 & $1 / 1990$ & twigs \\
\hline 61 & \multirow{2}{*}{ Cyclopia meyeriana Walp. } & ME1L & Matroosberg & Schutte 557 & $1 / 2 / 1990$ & leaves \\
\hline 62 & & ME2T & Matroosberg & Schutte 557 & $1 / 2 / 1990$ & twigs \\
\hline 63 & \multirow{4}{*}{ Cyclopia plicata Kies } & PL1L & Hoopsberg & Schutte $670 a$ & 09/1990 & leaves \\
\hline 64 & & PL2T & Hoopsberg & Schutte $670 a$ & 09/1990 & twigs \\
\hline 65 & & PL3L & Hoopsberg & Schutte $670 \mathrm{~b}$ & 09/1990 & leaves \\
\hline 66 & & PL4T & Hoopsberg & Schutte $670 \mathrm{~b}$ & 09/1990 & twigs \\
\hline 67 & \multirow{5}{*}{$\begin{array}{c}\text { Cyclopia pubescens Eckl. \& } \\
\text { Zeyh. }\end{array}$} & PU1L & Port Elizabeth & Schutte 685 & $22 / 9 / 1990$ & leaves \\
\hline 68 & & PU2T & Port Elizabeth & Schutte 685 & $22 / 9 / 1990$ & twigs \\
\hline 69 & & PU3L & Port Elizabeth & Schutte 686 & $22 / 9 / 1990$ & leaves \\
\hline 70 & & PU4L & Port Elizabeth & Schutte 687 & $22 / 9 / 1990$ & leaves \\
\hline 71 & & PU5L & Port Elizabeth & Schutte 688 & $22 / 9 / 1990$ & leaves \\
\hline 72 & \multirow{11}{*}{ Cyclopia subternata Vogel } & SU1L & Bloukrantz River & Schutte 683 & $21 / 09 / 1990$ & leaves \\
\hline 73 & & SU2L & Bloukrantz River & Schutte 683 & 9/1990 & leaves \\
\hline 74 & & SU3L & Kareedouw Pass & Schutte 505 & $22 / 01 / 1990$ & leaves \\
\hline 75 & & SU4L & $\begin{array}{l}\text { Prince Alfred's } \\
\text { Pass }\end{array}$ & Schutte 519 & $23 / 01 / 1990$ & leaves \\
\hline 76 & & SU5L & $\begin{array}{l}\text { Prince Alfred's } \\
\text { Pass }\end{array}$ & Van Wyk 939 & 20/2/1985 & leaves \\
\hline 77 & & SU6L & Outeniqua Pass & Schutte 639 & $9 / 1990$ & leaves \\
\hline 78 & & SU7T & Outeniqua Pass & Schutte 639 & $9 / 1990$ & twigs \\
\hline 79 & & SU8L & Outeniqua Pass & Schutte $690 \mathrm{~b}$ & 08/09/1991 & leaves \\
\hline 80 & & SU9F & Outeniqua Pass & Schutte $690 \mathrm{~b}$ & 08/09/1991 & flowers \\
\hline 81 & & SU10L & Witelsbos & Schutte 503 & $22 / 01 / 1990$ & leaves \\
\hline 82 & & SU11L & Elandsbos River & Schutte s.n. $1 b$ & 9/1990 & leaves \\
\hline
\end{tabular}

\subsection{Samples and Sampling}

The samples came from a collection of what are now historical materials that formed part of a comprehensive revision of the genus Cyclopia by Schutte [7], who also identified the materials (Table 2). De Nysschen [14] used part of this collection for a study of the main phenolic compounds in the genus, and reported the presence of mangiferin as the main constituent for the first time. The material was carefully stored at low humidity in a dark storeroom. We have previously shown [25] that the main phenolic compounds of commercial rooibos tea are remarkable stable, producing almost identical phenolic profiles after more than 80 years of storage.

\subsection{Extraction}

Depending on available material, ca. 300 to $500 \mathrm{mg}$ of dry plant material was soaked overnight in $50 \%$ methanol in water containing $1 \%$ formic acid $(2 \mathrm{~mL})$, using $15 \mathrm{~mL}$ polypropylene centrifuge tubes. The volumes of solvent were adjusted according to the available sample amount to $7.5 \mathrm{~mL}$ per 1 gram of sample. The samples were extracted in an ultrasonic bath $(0.5 \mathrm{~Hz}$, Integral systems, RSA) for $60 \mathrm{~min}$ at room temperature, followed by centrifugation for 5 minutes (Hermle Z160m, 3000 $\mathrm{g}$ ) and transferred to glass vials.

\subsection{Standards}

Standards were obtained from Sigma-Aldrich: mangiferin, citric acid, naringenin, hesperidin, kaempferol, quercetin and ferulic acid were analytically weighed out and dissolved in dimethyl sulfoxide (DMSO) and diluted in methanol to a calibration series of 2, 5, 10, 40, 50, 100, 200, $500 \mathrm{mg} / \mathrm{L}$. 


\subsection{UPLC-HRMS Analysis}

UPLC-HRMS analysis was performed using a Waters Synapt G2 Quadrupole time-of-flight (QTOF) mass spectrometer (MS) connected to a Waters Acquity ultra performance liquid chromatograph (UPLC) (Waters, Milford, MA, USA) with photodiode array detector. A Waters HSS T3, 2.1 $\times 150 \mathrm{~mm}$, $1.7 \mu \mathrm{m}$ column with water with $0.1 \%$ formic acid in line A and $0.1 \%$ formic acid in acetonitrile in line B. A flow rate of $0.25 \mathrm{~mL} / \mathrm{min}$ was used and the gradient started with $100 \%$ solvent A for 1 minute followed by a linear gradient to $28 \% \mathrm{~B}$ in 21 minutes and another linear gradient to $60 \% \mathrm{~B}$ in 8 minutes. The column was washed for 1 minute at $100 \%$ B and then re-equilibrated.

Data were acquired in $\mathrm{MS}^{\mathrm{E}}$ mode whereby a low collision energy scan is followed by a high collision energy scan to obtain both molecular ion $[\mathrm{M}-\mathrm{H}]$ and fragment data at the same time. During the high collision energy scan the collision energy was ramped from 20 to 60V. Electrospray ionisation was used in the negative mode and a scan range of 120 to 1500 was used. The desolvation temperature was set at $275^{\circ} \mathrm{C}$ and nitrogen was used as desolvation gas at $650 \mathrm{~L} / \mathrm{h}$. The capillary voltage was $25 \mathrm{~V}$ and the instrument was calibrated with sodium formate and leucine encephalin was used as lock mass for accurate mass determinations.

\subsection{Data Processing and Clustering}

The Markerlynx application manager of MassLynx ${ }^{\mathrm{TM}}$ version 4.1 software (Waters Corporation, Boston) was used to align the raw mass spectrometry data and convert it to retention time-mass pairs with signal intensity for each peak. Selected mass peaks from the mass spectra were normalised to compensate for the variance in concentration and ensure equal representation in the dataset, thereby facilitating comparative analysis. Normalisation involves scaling each sample vector using least squares normalisation (L2 norm), independently of other samples. Multivariate analysis was performed similar to [25].

Principal component analysis (PCA) was performed on the dataset. The number of PCA components was selected so that the amount of variance that needs to be explained is greater than two times standard deviation (95.45\%) data coverage. In traditional methods, the PCA components are visualised in pairs while the loadings plot for all PCA components is displayed simultaneously. However, all the selected PCA components need to be considered collectively for meaningful discrimination of the dataset. To achieve this, unsupervised hierarchical clustering analysis was then performed on the selected PCA components. An implementation of the Mean Shift clustering algorithm was chosen as it holds no intrinsic hypothesis about the number of clusters, nor the shape thereof. This is in contrast with to the classic K-means clustering approach where the number of clusters is predetermined. Mean Shift is a non-parametric centroid based algorithm, using a radial basis function (RBF) kernel, where each point in the feature space corresponds to the initial centroid positions. It iteratively updates centroids to be the mean of all the points within a given region, thereby discovering dense regions in the feature space, until convergence was achieved. The remaining set of centroids after convergence, being the cluster centres and the data points associated with the same centroid, are members of the same cluster.

Next, the loadings factors for each PCA component was analysed, to gain an understanding of which metabolites contributed to the most variation within the dataset. The loadings plots of the Markerlynx data as well as a manual peak picking process was used to identify the main compounds in the samples. The Targetlynx application manager was then used to create a smaller subset of 74 compounds that was processed in the same way, yielding similar results. The Targetlynx dataset is reported, as it contains data with tentatively identified compounds.

Supplementary Materials: The following are available online. Supplementary Figure S1: Correlation map between extracts of Cyclopia samples based on UPLC-HRMS data. Supplementary Figure S2: Dendrogram showing the relations of the different Cyclopia extracts based on Electrospray UPLC-HRMS data. Supplementary Table S1: Excel spreadsheet with areas of peaks relative to mangiferin detected in the Cyclopia extracts. 
Author Contributions: B.-E.V.W. and M.A.S. conceptualized the idea. B.-E.V.W. was responsible for the botanical aspects of the project, sample collection and selection. M.A.S. was responsible for the sample extraction, LCMS analysis and data interpretation and analysis. H.R. was responsible for the multivariate data analysis. H.L. was responsible for sample preparation and administration. K.M. was involved in data interpretation and analysis. B.-E.V.W., M.A.S., H.R. and K.M. were involved in writing reviewing and editing.

Funding: Financial support from the National Research Foundation (UID NR: 84442) of South Africa and the University of Johannesburg (to the SARChI National Research Chair in Indigenous Plant Use) are gratefully acknowledged. The Central Analytical Facility of Stellenbosch University is acknowledged for financial support.

Conflicts of Interest: Authors declare no conflict of interest.

\section{References}

1. Van Wyk, B.-E.; Gorelik, B. The history and ethnobotany of Cape herbal teas. S. Afr. J. Bot. 2017, 110, 18-38. [CrossRef]

2. Joubert, E.; Gelderblom, W.C.A.; Louw, A.; De Beer, D. South African herbal teas: Aspalathus linearis, Cyclopia spp. and Athrixia phylicoides-A review. J. Ethnopharmacol. 2008, 119, 376-412. [CrossRef] [PubMed]

3. Joubert, E.; Joubert, M.E.; Bester, C.; De Beer, D.; De Lange, J.H. Honeybush (Cyclopia spp.): From local cottage industry to global markets- the catalytic and supporting role of research. S. Afr. J. Bot. 2011, 77, 887-907. [CrossRef]

4. Hofmeyr, E.P.; Phillips, P. The genus Cyclopia Vent. Bothalia 1922, 1, 105-109. [CrossRef]

5. Kies, P. Revision of the Genus Cyclopia and Notes on Some Other Sources of Bush Tea. Bothalia 1951, 6, 161-176. [CrossRef]

6. Schutte, A.L. A taxonomic study of the tribes Podalyrieae and Liparieae (Fabaceae). Ph.D. Thesis, University of Johannesburg, Auckland Park, South Africa, 1995.

7. Schutte, A.L. Systematics of the genus Cyclopia Vent. (Fabaceae, Podalyrieae). Edinb. J. Bot. 1997, 54, $125-170$. [CrossRef]

8. Van Wyk, B.-E.; Gericke, N. People's plants: A Guide to Useful Plants of Southern Africa, 2nd ed.; Briza Publications: Pretoria, South Africa, 2018.

9. Van Wyk, B.-E. The value of chemosystematics in clarifying relationships in the genistoid tribes of papilionoid legumes. Biochem. Syst. Ecol. 2003, 31, 875-884. [CrossRef]

10. Van Wyk, B.-E.; Schutte, A.L. Phylogenetic relationships in the tribes Podalyrieae, Liparieae and Crotalarieae. Adv. Legume Syst. 1995, 7, 283-308.

11. Schutte, A.L.; Van Wyk, B.-E. Evolutionary relationships in the Podalyrieae and Liparieae based on morphological, cytological and chemical evidence. Plant Syst. Evol. 1998, 209, 1-31. [CrossRef]

12. Van Der Bank, M.; Van Wyk, B.-E.; Van Der Bank, H. Biochemical Genetic Variation in Four Wild Populations of Aspalathus linearis (Rooibos Tea). Biochem. Syst. Ecol. 1995, 23, 257-262. [CrossRef]

13. Van der Bank, M.; Chase, M.W.; Van Wyk, B.-E.; Fay, M.F.; Van der Bank, H.; Reeves, G.; Hulme, A. Systematics of the tribe Podalyrieae (Fabaceae) based on DNA, morphological and chemical data. Bot. J. Linn. Soc. 2002, 139, 159-170. [CrossRef]

14. De Nysschen, A.M.; Van Wyk, B.-E.; Van Heerden, F.R. The major phenolic compounds in the leaves of Cyclopia species (honeybush tea). Biochem. Syst. Ecol. 1996, 24, 243-246. [CrossRef]

15. De Nysschen, A.M.; Van Wyk, B.-E.; Van Heerden, F. Seed flavonoids of the tribes Podalyrieae and Liparieae (Fabaceae). Plant Syst. Evol. 1998, 212,1-11. [CrossRef]

16. Kamara, B.I.; Brand, D.J.; Brandt, E.V.; Joubert, E. Phenolic metabolites from Honeybush tea (Cyclopia subternata). J. Agric. Food Chem. 2004, 52, 5391-5395. [CrossRef]

17. Kokotkiewicz, M.; Luczkiewicz, A. Review: Honeybush (Cyclopia sp.)-A rich source of compounds with high antimutagenic properties. Fitoterapia 2009, 80, 3-11. [CrossRef] [PubMed]

18. De Beer, D.; Schulze, A.E.; Joubert, E.; De Villiers, A.; Malherbe, C.J.; Stander, M.A. Food ingredient extracts of Cyclopia subternata (honeybush): Variation in phenolic composition and antioxidant capacity. Molecules 2012, 17, 14606-14624. [CrossRef]

19. Beelders, T.; De Beer, D.; Stander, M.A.; Joubert, E. Comprehensive phenolic profiling of Cyclopia genistoides (L.) Vent. by LC-DAD-MS and -MS/MS reveals novel xanthone and benzophenone constituents. Molecules 2014, 19, 11760-11790. [CrossRef] 
20. Roza, O.; Martins, A.; Hohmann, J.; Lai, W.; Eloff, J.; Chang, F.; Csupor, D. Flavonoids from Cyclopia genistoides and their Xanthine Oxidase Inhibitory Activity. Planta Med. 2016, 82, 1274-1278. [CrossRef]

21. Walters, N.A.; De Beer, D.; De Villiers, A.; Walczak, B.; Joubert, E. Genotypic variation in phenolic composition of Cyclopia pubescens (honeybush tea) seedling plants. J. Food Compos. Anal. 2019, 78, 129-137. [CrossRef]

22. Singh, S.P.; Ali, M.M.; Jain, G.K. High-throughput Quantification of Isoflavones, Biochanin A and Genistein, and their Conjugates in Female Rat Plasma using LC-ESI-MS/MS: Application in Pharmacokinetic Study. J. Sep. Sci. 2010, 33, 3326-3334. [CrossRef]

23. Yang, M.; Ye, W.; Meng, G.; Sabir, A.; Qiao, G.; Guo, X.; Ye, D. Rapid Characterisation of Flavonoids from

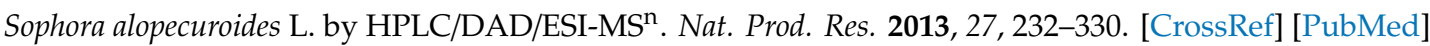

24. Stepanova, A.V.; Kotina, E.L.; Tilney, P.M.; Van Wyk, B.-E. Leaf and stem anatomy of honeybush tea (Cyclopia species, Fabaceae). S. Afr. J. Bot. 2012, 82, 123-128. [CrossRef]

25. Stander, M.A.; Brendler, T.; Redelinghuys, H.; Van Wyk, B.-E. The commercial history of Cape herbal teas and an analysis of phenolic compounds in historic teas from a depository of 1933. J. Food Compos. Anal. 2019, 76, 66-73. [CrossRef]

26. Ferreira, D.; Kamara, B.I.; Brandt, E.V.; Joubert, E. Phenolic compounds from Cyclopia intermedia (Honeybush Tea). J. Agric. Food Chem. 1998, 46, 3406-3410. [CrossRef] [PubMed]

Sample Availability: Samples of the compounds are not available from the authors. 